Review Article

\title{
Application of Molecular Approaches for Understanding Foodborne Salmonella Establishment in Poultry Production
}

\author{
Steven C. Ricke \\ Department of Food Science, Center for Food Safety, University of Arkansas, 2650 N. Young Avenue, Fayetteville, \\ AR 72704-5690, USA \\ Correspondence should be addressed to Steven C. Ricke; sricke@uark.edu
}

Received 27 April 2014; Revised 23 September 2014; Accepted 26 September 2014; Published 18 November 2014

Academic Editor: Sarah Lebeer

Copyright (C) 2014 Steven C. Ricke. This is an open access article distributed under the Creative Commons Attribution License, which permits unrestricted use, distribution, and reproduction in any medium, provided the original work is properly cited.

\begin{abstract}
Salmonellosis in the United States is one of the most costly foodborne diseases. Given that Salmonella can originate from a wide variety of environments, reduction of this organism at all stages of poultry production is critical. Salmonella species can encounter various environmental stress conditions which can dramatically influence their survival and colonization. Current knowledge of Salmonella species metabolism and physiology in relation to colonization is traditionally based on studies conducted primarily with tissue culture and animal infection models. Consequently, while there is some information about environmental signals that control Salmonella growth and colonization, much still remains unknown. Genetic tools for comprehensive functional genomic analysis of Salmonella offer new opportunities for not only achieving a better understanding of Salmonella pathogens but also designing more effective intervention strategies. Now the function(s) of each single gene in the Salmonella genome can be directly assessed and previously unknown genetic factors that are required for Salmonella growth and survival in the poultry production cycle can be elucidated. In particular, delineating the host-pathogen relationships involving Salmonella is becoming very helpful for identifying optimal targeted gene mutagenesis strategies to generate improved vaccine strains. This represents an opportunity for development of novel vaccine approaches for limiting Salmonella establishment in early phases of poultry production. In this review, an overview of Salmonella issues in poultry, a general description of functional genomic technologies, and their specific application to poultry vaccine developments are discussed.
\end{abstract}

\section{Introduction}

Salmonella induced gastroenteritis is the result of consumption of contaminated food and subsequent local infection in the gastrointestinal tract leading to symptoms of diarrhea, abdominal pain, and fever within 12 to 72 hours that can persist up to a week and in rare cases become fatal [1]. Salmonella infections are the leading cause of hospitalizations and deaths due to foodborne illness $[2,3]$. Consequently, foodborne disease resulting from exposure to serovars of Salmonella continues to be a major human health concern resulting in billions of dollars in annual costs [3]. Salmonella comes in contact with food production and preparation from a wide range of sources including animal and pet feed, during food processing, at retail establishments and in the home during meal preparation [1, 4-12]. Salmonellosis occurs worldwide and can originate from a wide range of raw food vehicles including most animal red meat, swine, poultry, eggs, vegetables, and produce as well as ready-to-eat foods [7, 1221]. Of these food sources, raw poultry products and eggs are considered a primary contributor to human exposure to foodborne Salmonella serovars with numerous salmonellosis cases attributed to these sources [2, 17, 18, 20-22].

Enteric or typhoid fever in humans occurs from waterborne exposure to serovars $S$. Typhi and Paratyphi, while several of the other S. enterica serovars are responsible for foodborne nontyphoidal salmonellosis [1]. Several Salmonella serovars have been associated with nontyphoidal human illness, but Salmonella enterica serovar Typhimurium along with $S$. Enteritidis, $S$. Newport, and $S$. Heidelberg have been the most commonly associated serovars with documented outbreaks $[18,20]$. In outbreaks directly linked to poultry $S$. Typhimurium and $S$. Enteritidis have been the most commonly identified serovars [20]. 
Salmonella serovars are able to survive under various niches ranging from diverse animal hosts, fruits, and vegetables to various livestock and food production environments; this ability has made the control of Salmonella colonization and transmission difficult $[7-9,14]$. The important characteristics of these serovars are that they can be harbored subclinically in livestock and poultry as asymptomatic commensal microorganisms, persist in the environment for long periods of time, and are thus difficult to control in the absence of a detailed knowledge of these organisms in that particular niche $[7,17,18,23]$. A wide variety of experimental techniques and strategies have been applied to develop the level of understanding of the ability of Salmonella to survive and cross contaminate multiple environments. Bacterial characteristics required for being able to exist in these environments have been studied extensively with a combination of laboratory and animal infection models. However, the availability of molecular technologies including sequencing and targeted mutagenesis has enabled the development of comprehensive functional genomics-based approaches to delineate the genetic requirements for Salmonella colonization, infection, and survival under environmental conditions that the microorganism is exposed to. The development and application of such novel functional genomics tools may reveal previously unknown vulnerabilities that can be explored to develop novel interventions and break the Salmonella transmission chain [24]. The objectives of this review are to discuss Salmonella occurrence in poultry production and the wide range of experimental methods that have been historically applied to understanding how Salmonella persists in poultry. The remainder of the review will be focused on more recent developments in functional genomics and their potential for general application to interventions and specific vaccine construction strategies to limit Salmonella establishment in poultry production.

\section{Salmonella in Broiler and Egg Production}

\subsection{Postharvest Contamination Routes: Broiler Meat. Salmonella} contamination in poultry production continues to be an ongoing problem both in laying hens and in broiler production [1, 20-22]. In broiler meat processing, multiple mechanical steps are involved in converting a live bird into a chicken carcass including scalding and subsequent removal of feathers, evisceration of intestinal organs, and eventual immersion in a chiller tank. There are a variety of opportunities for introduction and subsequent cross contamination of Salmonella spp. during poultry processing and these have been discussed in detail in previous comprehensive reviews $[10,19]$. However, a number of factors contribute to the difficulties associated with establishing consistent patterns of frequency and prevalence of Salmonella in these environments and on the carcasses themselves. For example, there may not only be differences in the frequency of Salmonella on carcasses but attachment sites on the carcass may also be variable which in turn could influence recovery when carcasses are rinsed for microbial analyses [25-27]. Early work suggested that prolonged immersion of chicken carcasses tended to enhance attachment of Salmonella [28-30]. In followup studies,
Lillard [30] demonstrated that prolonged water immersion of chicken skin enhanced transfer of Salmonella from the surface film outside the skin into the skin. Specific mechanisms had been proposed as being involved in bacterial attachment such as the presence of flagella and fimbrae, electrostatic attraction, or uptake of water but over time these were ruled out as primary mechanisms for Salmonella attachment [27-29, 31-34]. Based on several studies utilizing electron microscopy to examine chicken carcass tissue topography $[32,34-36]$ it was concluded by Lillard [27, 34] that some Salmonella may in fact become lodged in the crevices and ridges of poultry skin and thus are not only protected to some extent from application of disinfectants but less recoverable for detection based on carcass rinse sampling methods [2527]. In addition, after conducting multiple carcass rinses during various stages of processing, Lillard [26,27] concluded that bacteria become firmly attached to carcasses prior to the birds being processed. More recently, approaches such as online reprocessing involving inside-outside bird washers have been shown to be very efficient in removing pathogens from carcasses and have been incorporated into U.S. Food Safety and Inspection Service policy [20,37].

Based on the difficulty of removal of Salmonella from carcass surfaces, Lillard [27] suggested that while processing interventions can reduce cross contamination, further reduction of Salmonella carcass contamination in individual birds may require interventions during live bird production. However, part of the problem associated with assessment of postharvest contribution to contamination is that the preharvest origins of Salmonella can be fairly varied with primary sources being the fecal and alimentary tract contents (crop, cecal, and intestines) which in turn can contaminate the carcass during processing, particularly if one of the organs ruptures at some point [38-40]. Implementation of feed withdrawal prior to transportation to the processing plant was initiated as a means to decrease the total volume of the alimentary tract including contents thus reduce fecal contamination on carcasses, but this can lead to increases of Salmonella in the crops of chickens and potential for increased contamination at the processing plant [38-40]. This has been difficult to establish for a variety of reasons. First of all, most of the data that are generated from these types of samples are more along the lines of prevalence rather than quantitative estimations of resident populations [10]. In addition, the linkages between farm contaminations and processing plant levels are not well established and only recently have in-depth enumeration studies been conducted that have established a positive correlation between farm environmental levels of Salmonella and contamination at the processing plant [41]. However, as these authors [41] pointed out, this relationship decreased significantly as carcasses progressed through the processing plant with only $2.4 \%$ of the postchill carcasses positive for Salmonella. Such studies suggest that there is clearly a need to construct larger comprehensive data sets that rely not only on quantitation of Salmonella populations during the various phases of processing but more detailed characterization of the serovars involved. This will become more critical as regulatory and economic pressures continue to build towards lowering 
acceptable levels of Salmonella on chicken products [42]. Although improvements in molecular detection technologies have certainly benefited from advances in Salmonella genomics and sequence information, fundamental problems of cost, sampling, sensitivity, and practicality for routine analysis remain as barriers for implementation $[10,16,27,43-$ 46]. However, if more precise salmonellosis attributable to poultry or any other food source is to be achieved these barriers will need to be overcome $[10,16]$.

2.2. Postharvest Contamination Routes: Eggs. While routes for $S$. Enteritidis contamination of table eggs have also been extensively documented in numerous reviews there is evidence that other serovars are associated with eggs as well [21, 23, 47-50]. Likewise, the majority of the focus on Salmonella contamination in eggs has focused on transovarian vertical infection mostly by serovar Enteritidis of laying hens during egg production $[9,22,23,50-56]$ and there has been less emphasis in recent times on external shell horizontal contamination during egg processing. This is in part due to the advancements in understanding the mechanisms for external contamination by spoilage bacteria and Salmonella in hatching and table eggs from fundamental research on both types of eggs along with the subsequent improvements made in table egg processing over the past half century in the U.S. and elsewhere [21-23, 57-65].

Messens et al. [66] classified the factors associated with Salmonella penetration through the egg shell as either intrinsic (presence of cuticle on egg, shell quality, and membrane characteristics) or extrinsic (exposure to bacterial levels and types, and physical treatment of eggs such as temperature, moisture, and storage conditions). Certainly the presence of egg shell defects and cracks that occur either during processing or as a result of exposure to egg washing chemicals is conducive to egg contamination and the associated risks have been documented accordingly [65, 67-69]. However, the necessity for an intact cuticle which can be easily damaged and at least partially removed during egg processing is less clear cut although this may change now that proteomic analysis has revealed the presence of several antibacterial proteins in the cuticle $[66,70]$. As more has become known on the impact of environmental conditions, several suggestions have been made to design egg washing approaches that limit available iron, maintain alkaline $\mathrm{pH}$, and administer wash waters held within a certain temperature range above the egg temperature at all times followed by cold storage of eggs in retail markets $[22,58,63,66,71-75]$. These conditions appear to be critical in commercial operations as Salmonella has been isolated on eggs from egg processing plants when $\mathrm{pH}$ of the egg wash water was less alkaline $[63,76]$. However, both egg washing and subsequent refrigeration of stored eggs are not practiced uniformly worldwide and remain controversial in some countries $[22,63]$.

Risk of Salmonella external contamination of eggs during egg processing does still exist in the U.S. and other developed countries. In-line egg processing facilities where the egg processing facilities are physically connected to the egg layer operation, off-line operations where they are not physically connected, and mixed-line operations that include a combination of in-line processing as well as externally shipped in eggs have been shown in several studies to be a source of Salmonella contamination with or without egg washing [76-78]. In addition, numerous opportunities for general microbial cross contamination occur in these types of operations as the eggs move through the processing facilities $[79,80]$. In a series of studies on mixed-line and offline egg processing facilities, Musgrove and coworkers [78, 81] demonstrated that metal carts with unpainted plywood shelves, commonly referred to as nest run carts could serve as sources of microbial cross contamination.

Cross contamination can apparently occur from the farm to the egg packing plant as well. Characterization of Salmonella cross contamination of eggs transported from farms to whole sale and retail markets located in North India recovered $S$. Typhimurium as the predominant serovar with a higher incidence occurring in eggs collected from markets compared to fresh eggs from the farms [82]. This led them to conclude that surface contamination must have occurred during handling, storage, and transportation of the eggs from the farms to the market [82]. This was supported by earlier work [83] where Salmonella spp. were recovered from egg shells, egg contents, and egg trays in South India retail markets and these authors concluded that reused egg trays were a potential risk for exposure to Salmonella. A comprehensive study on Salmonella frequency in samples collected from eggshells, egg contents, reusable egg trays, and associated environments in Thailand egg farms and markets suggested reusable egg trays as a potential source of horizontal transmission [84]. It appears that further Salmonella cross contamination can occur from conveyors, rollers, and associated equipment in egg packing plants such as those in the UK where egg washing is not practiced which would represent additional risk to egg retail markets [77].

A final consideration is the changing nature of egg retail markets. In a review of the current literature Holt et al. [85] pointed out that a movement away from caged laying house systems to enriched cage or cage free systems must be evaluated for their impact on food safety. This would be true for any alternative egg production systems such as free range (hut-paddock system), cage-free, and organic based operations that have been described in previous studies [86, 87]. Likewise with more commercial emphasis on local egg marketing in the U.S. some of these issues will need to be reexamined with the restrictions unique to these systems.

\subsection{Preharvest Contamination Routes: Broilers. Numerous} factors contribute to continued exposure of birds to Salmonella from the environment during the production cycle $[8,10,88$, 89]. Carriers for Salmonella during the conventional poultry production cycle can include a wide variety of sources including rodents and cats as well as insects which when present in poultry houses can serve as infected or mechanical carriers and potential sources of this pathogen to susceptible birds [5, $8,90,91]$. Less conventional poultry production facilities such as organic, pasture, or free range raised poultry where birds have more outdoor exposure represent potential contact with an even wider range of vectors and environmental sources $[92,93]$. In addition to Salmonella vectors, environmental 
transmission routes (aerosols, water) and reservoirs such as litter and feed play a key role in this dissemination. Aerosols in particular have been identified in several studies as a transmission route not only in broiler and layer houses but in hatcheries as well [94-98]. Part of the issue with these sources is the ability of Salmonella to survive for fairly long periods of times in some of the reservoirs that vectors and other carriers such as aerosols carrying Salmonella come in contact with. For example, Salmonella spp. have been demonstrated to survive several weeks in low water activity poultry feeds and litter $[4,6,99-104]$. As a result there is a multitude of sustained opportunities for birds to encounter Salmonella over fairly long time periods and some sources such as contaminated feed and litter could impact poultry throughout the production cycle including the breeder flocks $[6,8,105]$.

2.4. Preharvest Contamination Routes: Layer Hens. While in broilers several serovars have been isolated, $S$. Enteritidis has been the serovar most commonly associated with shell egg production and products containing eggs as a food ingredient $[20,21,49,64,106,107]$. S. Enteritidis has continued to persist with periodic increases and decreases in frequency as a primary table egg associated serovar identified with foodborne salmonellosis outbreaks [49, 108, 109]. Although other serovars such as $S$. Typhimurium and $S$. Heidelberg have been identified with egg contamination, $S$. Enteritidis has received most of the research attention because it appears to possess unique traits that make it particularly trophic towards physiological processes and reproductive tissues associated with the generation of the shell egg in the laying hen $[21,22,48,49,53,56,64]$. Consequently considerable effort has been made to document and describe the role that preharvest egg production plays in the generation of contaminated eggs and how this impacts commercial egg production.

A brief assessment of the routes of exposure of laying hens to $S$. Enteritidis during egg production is warranted to help understand the apparent association between this particular serovar and table eggs. While laying hen susceptibility to $S$. Enteritidis varies with age and physiological status, there are numerous opportunities for these birds to become exposed to $S$. Enteritidis not only during the egg laying cycle, but also prior to that during the growth and maturing of the laying hen from hatch onwards $[48,50-56]$. This is in part due to ongoing environmental exposure, housing, and presence of numerous vectors well known for carrying $S$. Enteritidis such as insects, mice, rats, and other persistent pests in laying houses $[8,22,85,110-115]$. In addition, poultry feed has been speculated over the years to be an important source for Salmonella spp. exposure to chickens at various stages of live production including breeder flocks [4, 6, 105-121]. Consequently, interest in more rapid detection methods specifically suitable for poultry feed matrices that can not only detect Salmonella spp. but potentially quantitate population levels have continued to be pursued over a number of years $[24,46$, 105, 122-127].

Nutritional management of laying hens during egg production can also be a major contributor to risk of exposure of susceptible birds to $S$. Enteritidis. Although it varies somewhat depending upon the balance between the price of eggs and the costs associated with egg production, egg laying flocks in the U.S. typically are maintained for more than one egg laying cycle $[50,128-132]$. In order to initiate an additional egg laying cycle, laying hen egg production is terminated by physiologically inducing a molt onto the hens giving the reproductive tract a resting period where eggs are no longer produced and the reproductive tract is essentially dormant followed by a restart of egg production $[129,130]$. These physiological changes that occur during molt are manifested not only in the reproductive tract but also in feathers as a changeover, alteration of bone metabolism due to fluctuations in calcium demand, and shifts in metabolism and immune responses that have been described in comprehensive detail in several reviews and will not be discussed further here [50, 130-134]. To achieve management controlled egg production by physiological manipulation of the reproductive tract in laying hens is usually done via alteration of the nutritional status and lighting schedule of the bird to cause overall physiological and hormonal shifts that signal a need to rest egg synthesis $[130,133,135,136]$.

Historically, molting was induced by simply removing all feed from the laying hen for a period of time until egg production was stopped for several days and subsequently egg production was restarted by bringing feed back to the hens $[129,130,137]$. Although this approach was a very effective means for providing the appropriate signals to the bird to physiologically respond and cease egg production, the emptying of the gastrointestinal tract in these birds was demonstrated in experimental challenge studies to cause them to be susceptible to colonization and infection by $S$. Enteritidis [54-56]. In this series of experimental challenge trials it was well documented that birds undergoing feed withdrawal after just a few days were easily colonized by $S$. Enteritidis and extensive organ invasion occurred including the ovaries $[9,56,138]$. Further investigation revealed that the conditions of the empty gastrointestinal tract and ceca were conducive to increased expression of $S$. Enteritidis virulence genes which aligned with increased host invasion and decreased fermentation activity and in some cases reduced levels of indigenous gastrointestinal tract bacteria $[9,56$, 138-140]. Due to animal welfare concerns, feed withdrawal molting is not allowed in the UK and Europe [137]. More recently in the USA, the United Egg Producers (UEP) no longer permit feed withdrawal molting and the UEP has led the effort to develop alternative molting approaches that do not involve complete removal of feed [137]. This will be discussed in a later section.

\section{Interventions to Limit Salmonella Establishment in Poultry Production}

3.1. Postharvest Interventions. Historically, much of the emphasis for limiting Salmonella contamination in poultry production resided in identification and management of poultry processing plant sites where microbial contamination was most likely to occur as well as application of interventions during the various stages of processing. Hazard Analysis of 
Critical Control Points (HACCP) programs were designed and implemented to systematically identify critical control points where microbial contamination occurs during processing and subsequently prevent and control that contamination to reduce foodborne pathogen risk associated with raw poultry product [141]. Since that time, considerable effort has been continued to refine hazard identification in the context of risk assessment of likelihood of exposure from consumption of food product and level of disease attributable to the foodborne pathogen $[11,142]$. Specific targets identified as important contributors to risk have included the level of fecal contamination which in turn led to concerted regulatory efforts to encourage and implement approaches for reducing the level of fecal contamination on carcasses [37].

During postharvest poultry production there is potential for variable survival and physiological responses of Salmonella spp. to environmental conditions that are both inherent with the processing plant as well as via various antimicrobial interventions applied during processing. Certain antimicrobials such as short-chained organic acid based compounds are known to elicit tolerance mechanisms in Salmonella spp. if they have been exposed to sublethal concentrations $[143,144]$. Organic acid resistance in Salmonella spp. can also lead to cross protection and subsequent resistance to other antimicrobial compounds [145]. This becomes more of a challenge in organic poultry processing where only a limited range of antimicrobials are approved for use [146, 147]. Consequently, systems incorporating multiple antimicrobials also known as "multiple hurdle" approaches have been proposed to prevent buildup of resistance in pathogens to one particular antimicrobial [148-150]. Theoretically, this has been believed to be an optimal approach but it remains unclear how to routinely design such approaches to work in a multitude of environments. Part of the problem is assessing what levels of antimicrobial exposure actually occurs in the environment. Therefore, even though numerous laboratory-based studies have demonstrated the potential for resistance development, it is much more difficult to determine how much development of certain antimicrobial resistances occurs under processing plant conditions.

It is anticipated that as more molecular profiling of Salmonella responses are conducted experimentally there will be opportunities to further elucidate mechanisms that contribute to the ability of Salmonella to persist in processed poultry and poultry processing environments [24, 150]. For example, transcriptomic work involving $S$. Typhimurium microarrays has revealed that combinations of thermal and organic acids are synergistic in inhibiting Salmonella and may involve membrane damage followed by the inability of Salmonella to mount a heat shock response $[151,152]$. Chemical composition of the food matrix may also be important. Chalova et al. [153] demonstrated that the formation of specific Maillard products in a simulated low water activity environment generated a transcriptomic response in S. Typhimurium that reflected bacterial cells experiencing starvation conditions. However, using molecular genomic screening methodology directly on surfaces such as chicken carcass surfaces remains problematic due to the difficulty of extracting enough nucleic acid material for conducting the analyses [154].
For postharvest interventions on shell egg production, efforts have mostly been focused on elimination of microbial and Salmonella contamination on the shell surfaces of eggs. Interventions have typically involved the application either as a spray, dip or in some cases as a foam in combination with some type of chemical sanitizer candidate that is known to possess antimicrobial properties. While there is considerable overlap between the choices of sanitizers used for hatching eggs versus table shell eggs, the evaluation criteria for acceptability differ with impact on mortality and hatchability being critical for hatching eggs, whereas table eggs are destined for human consumption and therefore any sanitizer used for these types of eggs must meet those standards. Historically, a wide range of chemical-based sanitizers have been screened for efficacy as potential control measures to limit Salmonella and microbial contamination of both table and hatching egg shell surfaces $[21,155,156]$. Although an incomplete list, sanitizer chemicals that have been screened as egg disinfectants over the years have included such compounds as cetylpyridinium chloride, chlorine, chlorine dioxide, hydrogen peroxide, n-alkyl dimethyl benzyl ammonium chloride, peroxyacetic acid, phenol, polyhexamethylenebiguanide hydrochloride, sodium hypochlorite, quaternary ammonium compounds, and trisodium phosphate just to name a few that have been experimentally tested [21, 22, 63, 67, 155-160].

As additional emphasis has been placed on limiting microbial and pathogen contamination on shell eggs, research efforts have become focused on potential alternatives that may offer unique mechanisms to achieve efficacy. More novel sanitizer approaches that may serve as potential control agents for reducing microbial and Salmonella populations on shell and hatching eggs include electrolyzed oxidized water solutions, peroxidase catalyzed sanitizers that generate bactericidal levels of iodine, chitosan-based egg shell coatings, and application of plant-derived antimicrobials [161-172]. Nonchemical-based interventions have focused on approaches such as exposure of intact table and hatching eggs to ultraviolet light irradiation, ozone, pulsed light, and gas plasma [22, 173-180]. Interest has also grown in applying biologically active agents that can, not only directly and specifically interact with the target pathogen such as Salmonella, but also completely eliminate the organism. Bacteriophages, historically, were considered an effective antimicrobial against most pathogenic bacteria and renewed interest has emerged as conventional antimicrobials have fallen out of favor in the public health sector. Bacteriophages are essentially viral particles capable of attaching and inserting their nucleic acid information into the bacterial cell via a series of proteins specifically designed to accomplish this multistep process. Once the viral genetic material has entered the bacterial cells they insert phage DNA into the bacterial chromosome ultimately using the bacterial replication mechanisms to produce multiple copies of the phage for further replication, subsequent lysis of the bacterial cell, and infection of neighboring bacterial cells. Obviously this ability of an antimicrobial agent to replicate and ultimately destroy a bacterial population offers numerous opportunities for practical application in the food industry. For use in eggs to limit Salmonella contamination, lytic 
S. Enteritidis bacteriophage single isolates or cocktails of several isolates have been mostly applied to fresh table eggs to eliminate the presence of the pathogen or administered in the gastrointestinal tract of young chicks to reduce colonization by this pathogen but some researchers have also examined the possibility of using bacteriophage to reduce $S$. Enteritidis in fertile eggs [181-186]. However, limits to this approach remain including the specificity of the bacteriophage to a fairly narrow genetic range of serovars and the inherent ability of the host bacterial cell to develop resistance to a respective phage which can become problematic with continued use.

Ultimately, developing more effective postharvest control measures for egg processing and Salmonella contamination will depend on achieving a better understanding of the interactions between Salmonella spp. and their association with the egg structure and composition. A few limited studies have been conducted to identify potential Salmonella genes that might be directly involved in shell egg contamination. Kwon et al. [187] using a transposon Tn5-based footprinting was able to identify several $S$. Typhimurium mutants that were unable to survive on the surface of shell eggs after incubation at $37^{\circ} \mathrm{C}$ for $24 \mathrm{hr}$. Lu et al. [188] screened a genomic $S$. Enteritidis library and isolated the yafD gene which appeared to impart enhanced survivability in the egg albumen. Although unable to define yafD's function they speculated that its putative protein sequence similarity to known exonuclease-endonuclease-phosphatase enzyme families may enable $S$. Enteritidis to repair DNA after exposure to the egg albumen nucleases. More recently, Shah et al. [189] screened a $S$. Enteritidis transposon insertion library and noted that mutants that had reduced invasiveness in Caco2 mammalian cells also exhibited diminished survivability in egg albumen.

Clearly, more studies need to be done to develop a more complete picture of not only the mechanisms involved in $S$. Enteritidis penetration and survival in shell eggs but to establish the sequence of events that occur during this process. Now that proteomics-based methods are being used to study components of the egg such as the cuticle as discussed earlier, the possibility to expand this type of approach to changes that occur during exposure of shell eggs to bacterial pathogens may reveal unique interactions that occur between the egg and the respective pathogen. This may help to develop better control measures as well as predicting when contamination is more likely to occur. This could be important for further assessing risk. Much of the risk modeling that has been done, thus far, has identified terminal egg product processes such as rapid cooling and liquid whole egg pasteurization as having a major impact on substantially reducing the outbreaks associated with $S$. Enteritidis contaminated eggs [190, 191]. However, as more detailed biological information is obtained, the possibility exists of deriving more comprehensive risk models that can be used to predict and factor in when and how much Salmonella contamination may occur during egg production and processing.

3.2. Preharvest Interventions. The exposure of chickens during egg production and broiler grower cycles to Salmonella is considered to be quite complex since the susceptibility of birds to Salmonella infection varies over the course of the production cycle thus altering the infectious dose of Salmonella in exposed birds. More specifically, it is fairly well established that young newly hatched birds that have minimally developed gastrointestinal tract microflora are highly susceptible to colonization and infection by Salmonella in low numbers [192-195]. Given the vulnerability of young chicks, it is not surprising that many of the preharvest intervention approaches have focused on minimizing their exposure. For example, numerous control measures have been suggested for poultry feeds over the years including acids and other antimicrobial additives that can be directly added into the feed as well as physical processing such as irradiation and thermal exposure $[6,118,119,144,196-$ 198]. Ensuring Salmonella free-feed would be considered a fairly expensive avenue in general broiler and layer flock populations but might make economic sense at more critical junctures of vertically integrated poultry production such as the breeder and parent stocks [105].

Interventions administered to chicks soon after hatch have also been used as a rationale for introduction of probiotics and competitive exclusion cultures to accelerate development of gastrointestinal tract microflora that might serve as a barrier to Salmonella establishment [199-208]. Probiotic cultures have been examined in numerous studies for control and prevention of Salmonella establishment in poultry and the development of these cultures has been reviewed extensively elsewhere and will only be briefly discussed here [204, 206-210]. As expected, most of the focus in poultry was historically on administration of cultures in young newly hatched broiler chickens to limit S. Typhimurium [201, 203, 211-214]. In general, probiotic cultures appear to be effective for $S$. Typhimurium although other serovars have not been examined nearly as extensively. However, some of these same types of cultures and approaches do appear to be effective in limiting $S$. Enteritidis colonization in either broiler or layer chicks [202, 215-219]. As probiotic cultures have evolved, the trend has moved away from the more complex multibacterial species based probiotic cultures to simpler single species-based approaches that have been shown to be easier to administer commercially and more robust for practical management purposes. In particular, Bacillus spore-based probiotic cultures have recently become attractive due to their potential ability to withstand heat processing associated with feed preparation [208].

However, under certain circumstances adult birds can become easily infected as well. For example, as discussed earlier, when egg laying hens were induced to molt via complete removal of feed over several days, this was eventually demonstrated to be problematic for enhancing colonization of $S$. Enteritidis [56]. The concept that the resulting changes in the layer hen gastrointestinal tract from feed removal altered the microbial gastrointestinal tract ecology sufficiently that the birds were more systemically infected by $S$. Enteritidis intuitively led to the idea that retaining some sort of fermentable matrix in the gut lumen might prevent this $[56,131,138,220]$. Consequently, a series of studies demonstrated that decreased colonization occurs only when some sort of molt feed mixture or dietary supplement 
was provided to sufficiently support the fermentative gastrointestinal tract population [9, 56, 131, 135-140, 221-225]. It was concluded that formulating a nutritional balance in the laying hen diet between providing sufficient substrates for the gastrointestinal microflora but still physiologically shift the hen into a reproductive resting state was necessary. This, in turn, led to the development of a multitude of dietary strategies that would still induce an effective molt but retain sufficient gastrointestinal microbial activity [50, 56, 131]. Dietary approaches that limited $S$. Enteritidis and induced molt have been described and discussed extensively elsewhere but typically included manipulation of nutrient content, alterations in mineral content such as addition of zinc, or increasing the level of fiber in the diet using ingredients such as alfalfa alone or in some cases combined with prebiotics or lactose $[50,55,56,130-132,135,136,139$, $140,220,222,224-230]$. Ultimately, these dietary strategies were attempts to target the hen physiologically while avoiding extensive disruption of the gastrointestinal microflora.

In summary, there are a variety of strategies and approaches either currently employed or potentially available to limit Salmonella preharvest establishment in egg laying and broiler flocks. As with most food animal production systems implementation of multiple interventions and management choices would appear to provide the best opportunities for limiting dissemination of Salmonella both among birds within a flock as well as across multiple flocks. Likewise, early prevention of Salmonella establishment in breeder flocks prior to hatching of chicks and during early stages of chick growout for either broilers or layer hen replacement would represent a highly effective means to limit vertical dissemination of this pathogen in commercial poultry flocks. Strategies have been explored in attempts to either prevent establishment of Salmonella in laying hens at various stages of the production cycle or eliminate already established Salmonella. Attempts have been made to protect birds against Salmonella using a variety of live and attenuated vaccines that were specifically designed to limit Salmonella colonization and infection in young birds via resistance immunologically [231-233]. As more emphasis is being placed on preharvest prevention of Salmonella colonization there will be further need to develop and expand preventative interventions such as vaccines. However, this will require not only a better understanding of the mechanisms involved in Salmonella infection of birds but also more precise experimental approaches for defining host pathogen relationships. The following sections address current experimental methods for assessing Salmonella infection of poultry, followed by the use of functional genomics to delineate phenotype responses in Salmonella and finally the specific application of functional genomics and targeted mutagenesis to the evolution of vaccine development.

\section{Assessment of Salmonella Establishment in Poultry Production}

Assessing effective control measures and impact of exposure to Salmonella in poultry is further complicated due to the complex nature of Salmonella pathogenesis. In vivo
Salmonella infection models involving the use of a marker strain that carries gene encoding an easily selectable phenotype such as a unique antibiotic resistance profile have been routinely used in both laying hens as well as broilers for a wide range of applications [8, 9, 138, 139, 201, 203, 220, 222$225,229,230,234]$. Essentially the use of such genetically modified strains of Salmonella allow for ease of recovery in selective media against a highly complex background of non-Salmonella microflora by simply incorporating the corresponding antibiotics in the selective media. This is critical if quantitation of the Salmonella strain recovered from the infected bird is needed to estimate colonization impact and assess the effectiveness of potential interventions. However there are limitations with such studies not only in terms of availability of marker strains for different serotypes but also a more general concern as to whether antibiotic resistance could influence or alter the marker strain's infectivity compared to the corresponding wildtype isolate. To circumvent some of these limitations numerous attempts have been made over the years to create appropriate in vitro experimental models to simulate in vivo Salmonella pathogenesis. Anaerobic growth cultures that use either a batch or continuous incubation system have been used to assess Salmonella response to the presence of poultry cecal organisms but some type of marker strain is needed to estimate the Salmonella populations from these mixed culture backgrounds [212, 213, 235]. Pure culture studies involving either batch or continuous culture systems have also been conducted with Salmonella to delineate certain physiological factors but these do not precisely replicate the background matrices that Salmonella would be exposed to in the gastrointestinal tract [9,236-242]. Tissue culture has been historically useful to identify key virulence genes associated with attachment, invasion, and intracellular pathways as well as factors that influence these properties. However, it is difficult to screen a large number of variables and there remains some question as to whether tissue culture studies can serve as exact models for in vivo conditions [243-250].

As genetic techniques have developed, more detailed answers to Salmonella pathogenesis from both in vitro and in vivo systems have emerged. The ability to construct gene reporter fusion systems by combining key regulatory genes with structural genes encoding $\beta$-galactosidase, luciferase, or fluorescent green proteins has allowed for quantitative expression assessment when Salmonella strains carrying the reporter-fusion gene were exposed to different external and environmental conditions [251-261]. While there are some constraints with $\beta$-galactosidase fusion strains when used in certain backgrounds where non-Salmonella bacteria may also possess $\beta$-galactosidase genes, the luciferase and fluorescent green protein-based fusion Salmonella strains are usually detectable in most environmental settings. However, in general all of these strains are limited by the availability of fusion constructs that represent the spectrum of possible genetic elements involved in the virulence process. More recently quantitative polymerase chain reaction (PCR) assays have greatly expanded the ability to assess a wider range of genes in vivo and have been used in several poultry-based studies to determine virulence gene expression $[126,139,262]$. 
This information still represents a limited idea of overall Salmonella genetic capacity to respond to differing conditions in poultry production. For instance, during the poultry production cycle, Salmonella could encounter osmotic stress, temperature and $\mathrm{pH}$ fluctuations, desiccation, and starvation as well as exposure to high pressure and chemical decontaminants such as organic acids [6, 10, 88, 144, 146-149]. Considering overlapping stress signals that exist in both host environments and food production systems, there should be common pathways in bacterial cells that are essential for survival in both food environments and human hosts. However, factors uniquely associated with food environments more than likely also exist. Developing a detailed understanding of the unique genetic pathways essential for survival of Salmonella and other foodborne pathogenic bacteria in all phases of food production systems has the potential to provide the basis for the development of target-specific and more effective preventative and intervention strategies.

Traditionally, the development of intervention agents has been based mainly on screening for natural compounds exhibiting antibacterial properties. However, such broad cellbased screening usually does not provide information on the respective biochemical targets, which in turn hinders efforts to optimize each compound on the basis of structure-activity relationships [263]. To overcome this obstacle, the pharmaceutical industry redirected its antibacterial discovery approach in the early 1980's from screening for antibacterial activity to inhibiting specific biochemical targets [264]. The molecular targets of most antibiotics developed by whole cellbased screening are the essential gene products, which still remain important targets for development of novel antibiotics. Inhibition of those essential functions usually leads to eradication of the bacteria in the infected hosts. However, the bactericidal activity in those antibiotics is also a major factor in the emergence of antibiotic resistance bacteria in recent years [264]. In an effort to reduce the rate of resistance development, the bacterial genes that are not essential for in vitro growth but required for survival in infected host tissues have been suggested as alternative targets. Such in vivo essential gene products are more likely to provide a relatively narrow therapeutic range, thereby decreasing the likelihood of selection for broad antibiotic resistance.

In addition, there are not only different serotypes that can emerge but even subtle strain and serovar differences in stress response and virulence gene expression which in turn could cause shifts in Salmonella prevalence and subsequent emergence of new isolates [17, 18, 265-268]. Not only is this an issue from a detection and surveillance standpoint but it may also represent sufficient changes in virulence and physiological properties that alter risk, impede traceability, and negatively influence intervention strategies. Sorting out and perhaps predicting evolution of such isolates requires a much more comprehensive analysis of the respective genetic sequences of many more strains and isolates [269]. For Salmonella this remains somewhat of a challenge because as Becker et al. [270] have pointed out Salmonella is difficult to target for antibiotic therapy due to the high degree of redundancy in metabolic pathways in conjunction with its infection cycle occurring in nutrient rich host environments.
This redundancy may in turn allow for multiple parallel pathways for the pathogen to simultaneously disseminate in an infected animal via different host tissues [271]. Consequently, identifying unique genetic factors in Salmonella essential for counteracting stresses at different stages of poultry production might be needed to overcome this metabolic resiliency. However, this would involve designing more precise intervention strategies that employ antimicrobial agents or combinations of agents that target specific cellular components that render the organism highly vulnerable and less likely to recover. Functional genomics offers up a potential means to accomplish this as Rohmer et al. [272] have suggested that genome analysis focus could be more directed toward metabolic genes associated with host-pathogen relationships and inhibition of virulence factors could serve as possible therapeutic targets to avoid selection for resistance.

This paradigm is similar to current human clinical research strategies involving the development of new antibiotics for emerging pathogens by focusing on extensive searching for novel ecological sources for natural antimicrobial products as well as redesigning/modifying core structures of known antibiotics $[273,274]$. Continued advances in a variety of genetic functional screening techniques coupled with high throughput sequencing approaches have now made it possible to contemplate a much more comprehensive resolution to understanding the complex nature of biological systems such as Salmonella-host relationships [272, 275-278]. These approaches should help uncover some of the more subtle nuances in pathogenesis mechanisms and in turn achieve a better understanding of how Salmonella interacts with its poultry host $[278,279]$. The following sections will discuss these developments in general terms and how they might be used for understanding foodborne Salmonella functionality and subsequent application in vaccine development.

\section{Functional Genomics and Applications in Salmonella}

5.1. General Concepts. Genomic expression analyses can identify genes expressed under certain conditions but cannot define and/or identify genes that are required for survival in that particular niche. Therefore, a more direct way of finding the required genes is the use of genetic mutagenesisbased approaches that directly screen the genome to identify functionality with specific open reading frames on the chromosome. This type of functional genomics can be pursued by either forward or reverse genetic approaches [280]. Forward genetics essentially involves generation of random mutations in the organism of interest by a mutagenesis agent or biological mutagenic entity such as transposons, profiling the resulting mutants for detectable phenotype changes and identifying the gene(s) encoding the phenotype via location of the mutation [280]. Reverse genetics takes advantage of the increasing availability of large scale sequences of bacterial genomes to provide a platform for targeting a specific genetic change at a particular site in the genome via gene inactivation or deletion and assessing potential phenotype responses [280, 281]. 
Many of the more recent molecular applications in Salmonella associated with poultry have involved use of targeting specific genes to generate mutants that lack certain key functions related to their ability to establish in birds. Much of this effort has been directed specifically towards designing Salmonella vaccine strains which can successfully initiate an optimal immune response resulting in an immunized bird that resists future infections by nonvaccine Salmonella isolates. Historically, there have been a number of gene candidates that were believed to be appropriate targets, but as functional genomics and targeted mutagenesis methods have become more sophisticated better targets have been identified. These efforts have become more critical as the preharvest control measures have been identified as one of the avenues to be emphasized by the U.S. Food Safety and Inspection Service agency for overall control of Salmonella in poultry [282]. Of the preharvest approaches that have been characterized in the United Kingdom, O'Brien [283] concluded that the mass poultry Salmonella vaccination programs appeared to be the greatest contributor to the impressive fall in the number of cases occurring in that country since the late 1990's. Consequently, there is renewed commercial interest in the further development of more effective Salmonella vaccine strains. Some of these developments and the application of targeted mutagenesis will be described in the following sections.

\subsection{Targeted Mutagenesis and Salmonella Vaccine Develop-} ment in Poultry. In addition to conducting fundamental reverse genetic studies to achieve a better understanding of the specific phenotype response that an organism such as Salmonella might elicit after targeting a particular region of the chromosome more specific applications such as optimizing vaccine strain construction are possible. In poultry, Salmonella vaccination programs to limit the dissemination of foodborne serotypes have been developed over a number of years using either inactivated (killed) Salmonella or attenuated Salmonella strains [233, 284, 285]. Barrow et al. [285] summarized the properties of an ideal Salmonella vaccine that should include among other characteristics: (1) prevention of establishment of Salmonella, (2) minimization of persistence of Salmonella excretion and avoiding carriers (3) possession of ease of administration; (4) stimulation of immunity against target Salmonella and related serovars and the resulting immune resistance be passed onto the progeny; (5) exhibition of genetic stability of the live attenuated vaccines, and (6) no deleterious side impact on the host. Historically, heat killed Salmonella vaccines have been shown to provide protection but with somewhat variable results [285]. This may in part be due to their inability to trigger a cell-mediated immune response by the host as well as the destruction of some of the more fragile antigens during the heating process $[233,285]$.

Live Salmonella vaccine preparations have enjoyed widespread use and possess several advantages over their dead counterparts including their ability to elicit cellular and humoral immune responses in the host and when administered orally, engage mucosal immunity similar to what the host encounters with the corresponding foodborne pathogen [233, 286-288]. The key to optimizing live vaccine effectiveness in the respective host is to reduce (attenuate) virulence while retaining the immunogenicity by constructing a vaccine strain with decreased ability to grow in the host but still replicate sufficiently to persist long enough to trigger protective immunity [289]. Attenuation is typically achieved by mutagenesis of metabolic biosynthetic pathways such as those encoding synthesis of amino acids and purines or deletion of genes encoding specific virulence factors that limit the ability of the resulting mutant to survive for sustained periods of time but remain capable of inducing a sufficient immune response from the host animal to perpetuate immunity [233, 286, 289-291]. Historically, chemical or ultraviolet light induced mutagenesis approaches were used to generate these types of mutants but much more precise biological recombinant mutagenesis techniques are now employed to target specific gene sites [286, 289].

More recently Bohez et al. [292, 293] used the lambda Red approach described by Datsenko and Wanner [294] to promote recombination and generation of $S$. Enteritidis deletion mutants in hilA and sipA genes, respectively in Salmonella Pathogenicity Island (SPI-1) and the ssr A gene in SPI-2. Bohez et al. [293] selected these genes for potential vaccine development based on their decreased ability to colonize host tissues. This fits with their functionality in virulence expression as HilA is one of the important transcriptional activators responsible for coordinating regulation of invasion by environmental and regulatory factors, SipA is an actin-binding protein which stabilizes actin polymers at the interface with host cells, and SsrA is the sensor of the two-component secretion regulator protein for SPI-2 [251, 276, 295-297]. When young chickens were administered sipA and ssrA mutants, less internal organ colonization occurred versus wildtype while gut colonization remained consistent throughout the trials, and prevention of cecal colonization and internal organ infection after a wildtype $S$. Enteritidis challenge was maintained over the six-week period. Bohez et al. [293] concluded that the inability of these mutants to be cleared would be impractical for commercial application. However, the hilA mutant showed more promise as it was cleared from the gut after 4 weeks and although protection from gut colonization by the challenge strain was maintained for only 9 days, prevention of internal organ infection occurred over the entire 6-week period [293]. In a followup trial, long term (6 weeks) reduction in pathogen transmission among seeder birds (5 birds inoculated with the challenge wildtype $S$. Enteritidis) and contact birds (20 birds not inoculated with the challenge wildtype $S$. Enteritidis) was also demonstrated after birds had initially received the hilA mutant strain [298].

Karasova et al. [299] also used a PCR inactivation approach to conduct a comparative analysis of $S$. Enteritidis mutants generated for all 5 SPIs for vaccine potential using mice and concluded that all SPI-1 mutants generated (hilA, $\operatorname{sip} A, \operatorname{sip} B$, and $a v r A$ ) as well as other mutants identified with epithelial cell invasion $(\operatorname{sop} B$ and $\operatorname{sop} A)$ remained virulent in mice, while $h t r A$ appeared to be an optimal candidate due to its balance between attenuation and immunogenicity. This approach was taken a step further in chickens, where $S$. Enteritidis mutants were generated, each missing one of 
the 5 SPIs, as well as a mutant missing all 5 SPIs [300]. They demonstrated that even in the absence of all 5 major SPIs the resulting mutant could still become established in the ceca but systemic infection of internal organs (liver and spleen) required both SPI-1 and SPI-2. Dieye et al. [301] generated similar deletion mutants for S. Typhimurium SPI- 1 and 2 and infected one-week-old chickens with either a mixture of the two mutants or mixtures of the respective mutant and the wildtype strain. They [301] concluded that that while SPI-1 could be identified with colonization of the cecum and spleen, SPI-2 was only associated with spleen infection and not cecal colonization. They also noted that, in the absence of SPI-1, SPI-2 inhibited cecal colonization and that SPI-1 appeared to be more of a contributor to spleen infection, which, as they also pointed out, differed from mice studies where SPI- 2 is considered to be more critical for systemic infection. Based on these results and previous research by others Dieye et al. [301] speculated that these differences in hosts may be related to the severity of the disease and the extent of systemic infection versus infections that only result in asymptomatic carriage.

It is conceivable that both serovar and host are important contributors to the resulting respective virulence gene involvement. Evidence of this has been generated from both in vivo and in vitro studies. Karasova et al. [302] reported that when genes sodCl and $s p v B C$, associated with highly invasive Salmonella serotypes, were deleted in S. Enteritidis, virulence of the resulting mutants were reduced in mice but not chickens. They confirmed that this was consistent with serotypes $S$. Infantis, $S$. Hadar, and $S$. Agona which do not possess genes sodCl and $s p v B C$. Using porcine cell lines Volf et al. [303] demonstrated that incubation of cells with either wildtype $S$. Typhimurium or a SPI-2 ssrA mutant induced cytokine response when quantified by real time (RT)-PCR, but the cytokine was not induced for the SPI-1 hilA mutant. When examining chicken macrophage cells, He et al. [304] observed suppression of nitric oxide production by $S$. Typhimurium and $S$. Enteritidis but not $S$. Heidelberg, S. Kentucky, and S. Senftenberg even though all 5 serotypes are commonly isolated from poultry. Strain and isolate differences in virulence properties have also been noted for both $S$. Typhimurium and $S$. Enteritidis serovars [305-307]. When these studies are considered collectively, there are implications for further refinement in vaccine development as the respective animal models used will probably continue to reveal further nuances both in the host defense mechanisms as well as the complexity of Salmonella virulence counterresponses and suggest additional potential vaccine targets [308-311].

5.3. Targeted Mutagenesis and Salmonella Carrier Vaccine Development in Poultry. As an understanding of Salmonella pathogenesis and host immune responses evolved and vaccines specifically targeting Salmonella achieved more sophistication it became clear that multivalent vaccines could be genetically constructed to generate host immunity not only to Salmonella antigens but also to non-Salmonella antigens [286]. The ability of Salmonella to colonize the gastrointestinal tract, cross gastrointestinal tract epithelial mucosal barriers, and interact intracellularly in host cells makes it an ideal carrier for presentation of heterologous antigens to the target host's immune system [312-316]. Many of the early Salmonella heterologous vaccine constructs involved use of Salmonella biosynthetic gene mutants transformed with external genetic elements such as antibiotic resistant plasmids carrying genes encoding a myriad of non-Salmonella antigens that were of interest for targeting the immune system of the host [317-320]. However, several problems emerged with these approaches for vaccine administration. The primary concern was the use of antibiotic resistance as a means to retain the plasmid under these conditions where it may be a risk for dissemination of antibiotic resistant bacteria in the environment and thus would be considered a regulatory issue [284, 320-323]. In response to this concern, nonantibiotic markers have been developed for Salmonella vaccine strains carrying plasmids as well as balanced lethal plasmid stabilization by constructing a plasmid containing not only the heterologous antigen encoding gene(s) but also a biosynthetic gene that complements an auxotrophic gene on the chromosomal gene [324-329]. To optimize heterologous antigen expression in Salmonella vaccine strains, varying the copy number of the expression plasmid has been employed $[330,331]$. However, it has been pointed that a vaccine strain carrying plasmids is not only vulnerable due to the metabolic burden/reduced fitness of the organism when introduced to a relatively hostile gastrointestinal tract environment but this may in turn serve as selective pressure to enhance the likely loss of the plasmid [321, 322, 330, 332].

To avoid plasmid vehicles for heterologous antigen expression altogether requires insertion directly into the chromosome in such a fashion that the resulting gene encoding the heterologous antigen is expressed optimally and stably to ensure a sufficient host immune response. Strugnell et al. [333] demonstrated that an E. coli cloning vector containing a $S$. Typhimurium aroC gene fragment with several unique restriction sites allowed expression of heterologous antigen encoding genes once inserted into the $S$. Typhimurium chromosome via homologous recombination. Over a decade later, significant improvements on this approach occurred when the bacteriophage-encoded recombinase systems were developed for directing homologous recombination and subsequently were utilized for a variety of mutational manipulations and genetic analyses of Salmonella [334, 335]. Husseiny and Hensel $[328,336]$ further modified the Red recombinase approach initially developed by Datsenko and Wanner [294] to construct functional expression cassettes that included either constitutive or in vivo activated promoters to direct heterologous protein encoding genes after simulataneous insertion in the Salmonella chromosome and simultaneous deletion of chromosomal genes. However, Husseiny and Hensel [336] concluded that constitutive expression of heterologous antigen could cause stability issues with the respective Salmonella carrier vaccine as well as overattenuation leading to an overall poor host immune response. Instead, they proposed development of promoters that controlled synthesis of the heterologous antigen only after induction at the target cell. The concept of enhancing host immune response to in vivo induced foreign antigens had been previously shown to 
increase IgG antibody levels only in mice immunized with a $S$. Typhimurium mutant carrying an inducible Pag-C alkaline phosphatase fusion protein encoding gene in the chromosome but not the constitutive carrying mutant [322, 337]. Husseiny and Hensel, [336] focused on the SPI-2 sse genes which encode proteins that are part of the type III secretion system responsible for survival of intracellular bacteria in the surrounding host cell [296]. They immunized mice and observed that the intracellular sseA promoter activated mutant strain when compared to its constitutive counterparts enhanced secreted and serum antibodies, increased T-cell proliferation as well as providing protection against Listeria monocytogenes infection. Stratford et al. [322] also reported increased antigen specific IgG responses in mice inoculated with an $s s a G$ promoter $S$. Typhi mutant but not when this promoter was replaced with a constitutive promoter.

As more is understood on the complexity of the immune system it is becoming clear that there is a need for more precisely defined heterologous antigen Salmonella vaccine carriers and that multiple antigens may need to be targeted to optimize and sustain the host immune response. Likewise accurate expression of foreign protein antigens during the immune response is critical if immunization is to be successful against the respective targeted infective agent. When Datsenko and Wanner [294] developed the Red recombinase system to disrupt and insert DNA into target host's chromosome the subsequent removal of the antibiotic resistance or FRT sequences leaves a residual sequence or "scar" in the target sequence. They pointed out that such remaining sequences would be problematic because of unintentional consequences such as recombination of a new PCR fragment with the FRT scar site rather than the newly targeted gene could occur given the limited requirement for homology. These residual or scar sequences represent other potential issues as well such as intereference with gene expression under certain conditions [338]. Several scarless strategies have been developed to resolve this including using marked cassettes for positive or negative selection which can be counter selected with markerless linear DNA via a second round of recombination [339-342]. Alternatively, a counterselection cassette containing an inducible gene encoding I Sce-I endonuclease and its recognition site along with an antibiotic gene can be used in the initial recombination event with the chromosomal target site, followed by induction of the endonuclease and generation of a double stranded break that serves as the site for the second round of recombination with a markerless homologous PCR fragment [338, 343-345].

Cox et al. [346] adapted these approaches to develop a scarless, site directed mutagenesis method for $S$. Enteritidis where longer sequence homologies of 100 to $1000 \mathrm{bp}$ appear to be required for efficient recombination versus 36 to $50 \mathrm{bp}$ for $E$. coli $[188,294]$. They combined an overlapping extension PCR, the Red recombinase system, along with the intermediary insertion of the I-SceI endonuclease as a counter selection marker to mediate the recombination of linear DNA with long flanking homology (200 to $300 \mathrm{bp}$ ) to $S$. Enteritidis genome sequences. The $S$. Enteritidis mutation by this system was a two-step process with homologous recombination of the linear DNA cassette containing the I-SceI site and kanamycin resistance gene undertaken in the first step. This was followed in the second step by replacement of this inserted fragment with a PCR fragment with a targeted insertion sequence along with a chloramphenicol resistant containing plasmid encoding the I-SceI endonuclease to cut the chromosome at the I-SceI and final selection of $S$. Enteritidis recombinant isolates that were chloramphenicol resistant and kanamycin sensitive. This method was applied to a series of studies designed to develop effective Salmonella foreign antigen carrier vaccines for limiting avian influenza and to serve as a polyvalent vaccine for multiple Salmonella serotypes in chickens and turkeys. Layton et al. [347] constructed a recombinant S. Enteritidis strain expressing the avian influenza M2e membrane protein and the CD154 peptide found on the surface of $\mathrm{T}$ cells that are involved in activation of antigen-presenting immune cells and used these to orally immunize day old chicks on day of hatch followed by a booster on day 21. Vaccinated chickens produced higher levels of M2e specific IgG that were increased further when also exposed to the expressed CD-154 peptide but were only protected when challenged with a low pathogenic avian influenza strain but not a highly pathogenic strain.

O’Meara et al. [348] reported that by day 21, turkeys immunized with various S. Enteritidis M2e/CD-154 combinations (CD154 peptides: turkey, human, and chicken) exhibited a higher M2e specific antibody level than negative (sterile saline) and positive ( $S$. Enteritidis wildtype) control birds but no M2e antibody differences were observed among the vaccine strains expressing the different CD154 peptides. Wolfendren et al. [349] reported that a S. Enteritidis recombinant expressing the CD154 peptide antigen along with a Salmonella flagellar filament protein (fliC) did not protect against a heterologous $S$. Typhimurium challenge in chickens. When M2e-fliC carrier vaccines were used to immunize turkeys, increases in M2e antibodies compared to the negative and positive controls occurred, but no differences among the $S$. Enteritidis vaccine treatments were observed [350].

Although numerous Salmonella-based vaccines developed for administration to poultry have been generated, consistent effectiveness remains somewhat elusive. Several issues remain including the ongoing need for multivalent Salmonella vaccines that are effective against a multitude of Salmonella serotypes [351]. This is somewhat difficult since serotypes continue to emerge and become predominant only to be replaced by another serotype. Consequently, achieving cross protection among serotypes remains an elusive target $[233,351]$. However, perhaps a better strategy may be to use the host animal as a means to screen for immune signals that are common signatures to systemic infection of Salmonella in chickens as has been done recently in murine and human Salmonella systemic infections $[352,353]$. Improvements in design of Salmonella carrier vaccines are also emerging that induce greater immune responses by using regulated in vivo attenuation as well as regulated delayed in vivo antigen synthesis [323]. 


\section{Conclusions}

Substantial advances have been made in the understanding of Salmonella spp. establishment and cross contamination in food system environments including poultry $[5,8,19,354]$. Likewise stresses occurring in the gastrointestinal tract that Salmonella is known to respond to have been identified [9, $246,272,314,354,355]$ and the concept that pathogenesis may be driven by nutrient scavenging may help to understand additional gastrointestinal cues [272]. However, as genetic analyses has become more sophisticated a better fundamental understanding has emerged on different aspects of the physiological ability of Salmonella to respond to environmental stresses during its entire life cycle [297, 315, 316, 356, 357]. For example, it is now becoming apparent that even fairly well characterized stress responses such as acid tolerance may in fact be further complicated as more pathways for adaptation have been identified, responses to different acids may differ, and not all Salmonella serovars may be either equally acid resistant and/or mount similar virulence responses in the presence of different acids [265-268, 358-364]. It is likely that such nuances and complexities will probably come to light for nonacid stress responses as more details become known about Salmonella physiology and functional genomics.

Salmonella can also use its own metabolism to manipulate its surrounding environment. Salmonella has been shown to change the environment in the gastrointestinal tract in an attempt to overcome colonization barriers by literally inducing inflammation to generate metabolities that alter energy metabolism in such a way that it can outcompete the fermentative gastrointestinal microbial consortium [365368]. Likewise, the ability of Salmonella to form biofilms complicates the development of intervention strategies since the biofilm matrix can be protective against environmental stresses as well as antimicrobials [19, 369]. Formation of biofilms by Salmonella is believed to be mediated by chemical compounds which function as quorum sensing signal molecules that serve as communication signals among bacterial populations by being released by some cells and subsequently internalized by other cells [370-372]. Biofilms can form on a multitude of hard surfaces such as glass and stainless steel [369]. It is unclear how important quorum sensing and biofilm formation are in food systems although several compounds have been isolated that are antagonistic to quorum sensing compounds [373]. For example, poultry meat-derived fatty acids have been identified as being inhibitory to a quorum sensor autoinducer [374]. The prevalence in food matrices of these inhibitors and their subsequent impact in biofilm formation remain to be determined. However, Salmonella biofilm formation does appear to be involved in adhesion on epithelial cells and is mediated by exopolysaccharide composition [369, 375, 376]. Conversely, the presence of the autoinducer AI-2 actually decreased $S$. Typhimurium in vitro mouse macrophage invasiveness [377]. A further complication may be the possible Salmonella strain variability influence on biofilm formation [378]. As more becomes known about the factors that influence biofilm formation, the role(s) these formations play in surviving environmental stresses as well as initial colonization in various niches will become clearer.
In poultry, more is now known about what factors influence the ability of Salmonella to colonize the bird's gastrointstinal tract and trigger systemic invasion $[17,18$, $22,354]$. More recently, the interactions between the host's immune system and pathogens such as Salmonella are becoming better understood and thus predictable [278, 281]. As more has become known regarding these different aspects of the dynamic Salmonella-host interface interactions, development of more effective intervention measures has become possible. However, despite these technological advances foodborne Salmonella occurring in poultry continues to be a potential source of foodborne disease in the public sector. Although a wide range of interventions have been developed, limitations remain in their effectiveness. Certainly some of this is attributable to the ability of Salmonella spp. to express resistance mechanisms and overcome individual intervention hurdles. However, there also appears to be differences in response to certain antimicrobials and environmental conditions, among not only serovars but also strains and isolates within serovars as well. In addition, historically it appears that different Salmonella serovars have emerged to become predominant and that this evolution of serovars may be an ongoing process in poultry production. This not only presents a challenge for development of detection technologies, but also makes it more difficult to design interventions that will broadly limit most Salmonella spp.

Advances in molecular-based research should provide some insight to differences at the genomic level that are responsible for Salmonella isolates and strains that are subtly distinguishable at the phenotype level. The number of Salmonella isolates that have been sequenced continues to grow and adding this information to the genomic data base for individual Salmonella serovars will certainly be helpful for resolving detection and intervention issues when only subtle differences exist among strains and isolates. However, sequencing a wide range of Salmonella genomes is only the beginning. Assessing genomic functionality beyond just the sequence is becoming more important to not only understand factors responsible for the complex interaction between the chicken host and the invading Salmonella but also to delineate what host characterstics trigger initiation of Salmonella pathogenesis and how Salmonella overcomes and/or circumvents host defenses. Such approaches represent a much more comprehensive strategy for not only studying Salmonella overall responses but also readily exploring complex genetic mechanisms of this important foodborne pathogen to survive and persist in poultry production as well as human food chains in general. These approaches also have utility for designing interventions. This becomes particularly critical when constructing more advanced vaccine strategies where a balance between maximum stimulation of the immune system and consistent removal of the candidate vaccine strain is required. High-resolution functional screening of the respective Salmonella genomes offers the opportunity to identify distinct genetic components responsible for different virulence mechanisms involved in the pathogenic pathway and precisely identify individual genes for targeted mutagenesis. Such approaches are now being more routinely employed and it is anticipated that understanding the genetic factors 
and survival mechanisms will continue to provide valuable insights for development of effective strategies to reduce Salmonella in poultry and poultry products.

\section{Conflict of Interests}

The author declares that there is no conflict of interests regarding the publication of this paper.

\section{Acknowledgments}

This review was partially supported by a United States Department of Agriculture-National Integrated Food Safety Initiative (USDA-NIFSI) Grant no. 2008-51110-04339, a USDASARE Grant no. LS11-245, and a U.S. Poultry \& Egg Grant no. F056 to author Steven C. Ricke.

\section{References}

[1] S. C. Ricke, O.-K. Koo, S. Foley, and R. Nayak, "Salmonella," in Guide to Foodborne Pathogens, R. Labbé and S. García, Eds., chapter 7, pp. 112-137, Wiley-Blackwell, Oxford, UK, 2nd edition, 2013.

[2] J. A. Painter, R. M. Hoekstra, T. Ayers et al., "Attribution of foodborne illnesses, hospitalizations, and deaths to food commodities by using outbreak data, United States, 1998-2008," Emerging Infectious Diseases, vol. 19, no. 3, pp. 407-415, 2013.

[3] E. Scallan, R. M. Hoekstra, F. J. Angulo et al., "Foodborne illness acquired in the United States-major pathogens," Emerging Infectious Diseases, vol. 17, no. 1, pp. 7-15, 2011.

[4] R. H. Davies and M. H. Hinton, "Salmonella in animal feed," in Salmonella in Domestic Animals, C. Wray and A. Wray, Eds., chapter 17, pp. 285-300, CABI Publishing, Wallingford, UK, 2000.

[5] C. J. Murray, "Environmental aspects of Salmonella," in Salmonella in Domestic Animals, C. Wray and A. Wray, Eds., chapter 16, pp. 265-283, CABI Publishing, Wallingford, UK, 2000.

[6] K. G. Maciorowski, F. T. Jones, S. D. Pillai, and S. C. Ricke, "Incidence, sources, and control of foodborne Salmonella spp. in poultry feeds," World's Poultry Science Journal, vol. 60, no. 4, pp. 446-457, 2004.

[7] S. L. Foley, A. M. Lynne, and R. Nayak, "Salmonella challenges: prevalence in swine and poultry and potential pathogenicity of such isolates," Journal of Animal Science, vol. 86, no. 14, pp. E149-E162, 2008.

[8] S. Y. Park, C. L. Woodward, L. F. Kubena, D. J. Nisbet, S. G. Birkhold, and S. C. Ricke, "Environmental dissemination of foodborne Salmonella in preharvest poultry production: reservoirs, critical factors, and research strategies," Critical Reviews in Environmental Science and Technology, vol. 38, no. 2, pp. 73-111, 2008.

[9] K. D. Dunkley, T. R. Callaway, V. I. Chalova et al., "Foodborne Salmonella ecology in the avian gastrointestinal tract," Anaerobe, vol. 15, no. 1-2, pp. 26-35, 2009.

[10] N. A. Cox, J. A. Cason, and L. J. Richardson, "Minimization of Salmonella contamination on raw poultry," Annual Review of Food Science and Technology, vol. 2, pp. 75-95, 2011.

[11] M. P. Doyle and M. C. Erickson, "Opportunities for mitigating pathogen contamination during on-farm food production," International Journal of Food Microbiology, vol. 152, no. 3, pp. 54-74, 2012.
[12] O. K. Koo, S. A. Sirsat, P. G. Crandall, and S. C. Ricke, "Physical and chemical control of Salmonella in ready-to-eat products," Agriculture, Food and Analytical Bacteriology, vol. 2, pp. 56-68, 2012.

[13] T. V. Suslow, M. P. Oria, L. R. Beuchat et al., "Production practices as risk factors in microbial food safety of fresh and fresh-cut produce," Comprehensive Reviews in Food Science and Food Safety, vol. 2, no. 1, pp. 38-77, 2003.

[14] I. B. Hanning, J. D. Nutt, and S. C. Ricke, "Salmonellosis outbreaks in the United States due to fresh produce: sources and potential intervention measures," Foodborne Pathogens and Disease, vol. 6, no. 6, pp. 635-648, 2009.

[15] M. C. Erickson, "Microbial risks associated with cabbage, carrots, celery, onions, and deli salads made with these produce items," Comprehensive Reviews in Food Science and Food Safety, vol. 9, no. 6, pp. 602-619, 2010.

[16] G. Mead, A. M. Lammerding, N. Cox et al., "Scientific and technical factors affecting the setting of Salmonella criteria for raw poultry: a global perspective," Journal of Food Protection, vol. 73, no. 8, pp. 1566-1590, 2010.

[17] S. L. Foley, R. Nayak, I. B. Hanning, T. J. Johnson, J. Han, and S. C. Ricke, "Population dynamics of Salmonella enterica serotypes in commercial egg and poultry production," Applied and Environmental Microbiology, vol. 77, no. 13, pp. 4273-4279, 2011.

[18] S. L. Foley, T. J. Johnson, S. C. Ricke, R. Nayak, and J. Danzeisen, "Salmonella pathogenicity and host adaptation in chicken-associated serovars," Microbiology and Molecular Biology Reviews, vol. 77, no. 4, pp. 582-607, 2013.

[19] E. Carrasco, A. Morales-Rueda, and R. M. García-Gimeno, "Cross-contamination and recontamination by Salmonella in foods: a review," Food Research International, vol. 45, no. 2, pp. 545-556, 2012.

[20] S. Finstad, C. A. O’Bryan, J. A. Marcy, P. G. Crandall, and S. C. Ricke, "Salmonella and broiler processing in the United States: relationship to foodborne salmonellosis," Food Research International, vol. 45, no. 2, pp. 789-794, 2012.

[21] Z. R. Howard, C. A. O'Bryan, P. G. Crandall, and S. C. Ricke, "Salmonella Enteritidis in shell eggs: current issues and prospects for control," Food Research International, vol. 45, no. 2, pp. 755-764, 2012.

[22] A. M. Galiş, C. Marcq, D. Marlier et al., "Control of Salmonella contamination of shell eggs-preharvest and postharvest methods: a review," Comprehensive Reviews in Food Science and Food Safety, vol. 12, no. 2, pp. 155-182, 2013.

[23] S. C. Ricke, D. R. Jones, and R. K. Gast, "Eggs and egg products," in Compendium of Methods for the Microbiological Examinations of Foods, S. Doores, Y. Salfinger, and M. L. Tortorello, Eds., chapter 46, pp. 1-11, American Public Health Association, 5th edition, 2013.

[24] S. C. Ricke, A. Khatiwara, and Y. M. Kwon, "Application of microarray analysis of foodborne Salmonella in poultry production: a review," Poultry Science, vol. 92, no. 9, pp. 22432250, 2013.

[25] H. S. Lillard, "Comparison of sampling methods and implications for bacterial decontamination of poultry carcasses by rinsing," Journal of Food Protection, vol. 51, pp. 405-408, 1988.

[26] H. S. Lillard, "Incidence and recovery of salmonellae and other bacteria from commercially processed poultry carcasses at selected pre- and post-evisceration steps," Journal of Food Protection, vol. 52, pp. 88-91, 1989. 
[27] H. S. Lillard, "Factors affecting the persistence of Salmonella during the processing of poultry," Journal of Food Protection, vol. 52, pp. 829-832, 1989.

[28] S. Notermans and E. H. Kampelmacher, "Attachment of some bacterial strains to the skin of broiler chickens," British Poultry Science, vol. 15, no. 6, pp. 573-585, 1974.

[29] H. S. Lillard, "Bacterial cell characteristics and conditions influencing their adhesion to poultry skin," Journal of Food Protection, vol. 48, no. 9, pp. 803-807, 1985.

[30] H.S. Lillard, "Distribution of, attached, Salmonella typhimurium cells between poultry skin and a surface film following water immersion," Journal of Food Protection, vol. 49, pp. 449-454, 1986.

[31] T. A. McMeekin and C. J. Thomas, "Retention of bacteria on chicken skin after immersion in bacterial suspensions," Journal of Applied Bacteriology, vol. 45, no. 3, pp. 383-387, 1978.

[32] C. J. Thomas and T. A. McMeekin, "Effect of water uptake by poultry tissues on contamination by bacteria during immersion in bacterial suspensions," Journal of Food Protection, vol. 47, no. 5, pp. 398-402, 1984.

[33] H. S. Lillard, "Role of fimbriae and flagella in the attachment of Salmonella typhimurium to poultry skin," Journal of Food Science, vol. 51, no. 1, pp. 54-56, 1986.

[34] H. S. Lillard, "Effect of surfactant on changes in ionic strength on the attachment of Salmonella typhimurium to poultry skin and muscle," Journal of Food Science, vol. 53, no. 3, pp. 727-730, 1988.

[35] C. J. Thomas and T. A. McMeekin, "Attachment of Salmonella spp. to chicken muscle surfaces," Applied and Environmental Microbiology, vol. 42, no. 1, pp. 130-134, 1981.

[36] C. J. Thomas and T. A. McMeekin, "Effect of water immersion on the microtopography of the skin of chicken carcasses," Journal of the Science of Food and Agriculture, vol. 33, pp. 549$554,1982$.

[37] J. Rasekh, A. M. Thaler, D. L. Engeljohn, and N. H. Pihkala, "Food safety and inspection service policy for control of poultry contaminated by digestive tract contents: a review," Journal of Applied Poultry Research, vol. 14, no. 3, pp. 603-611, 2005.

[38] B. M. Hargis, D. J. Caldwell, R. L. Brewer, D. E. Corrier, and J. R. Deloach, "Evaluation of the chicken crop as a source of Salmonella contamination for broiler carcasses," Poultry Science, vol. 74, no. 9, pp. 1548-1552, 1995.

[39] J. A. Byrd, B. M. Hargis, D. E. Corrier et al., "Fluorescent marker for the detection of crop and upper gastrointestinal leakage in poultry processing plants," Poultry Science, vol. 81, no. 1, pp. 70$74,2002$.

[40] D. E. Corrier, J. A. Byrd, B. M. Hargis, M. E. Hume, R. H. Bailey, and L. H. Stanker, "Presence of Salmonella in the crop and ceca of broiler chickens before and after preslaughter feed withdrawal," Poultry Science, vol. 78, no. 1, pp. 45-49, 1999.

[41] R. D. Berghaus, S. G. Thayer, B. F. Law, R. M. Mild, C. L. Hofacre, and R. S. Singer, "Enumeration of Salmonella and Campylobacter spp. in environmental farm samples and processing plant carcass rinses from commercial broiler chicken flocks," Applied and Environmental Microbiology, vol. 79, no. 13, pp. 4106-4114, 2013.

[42] M. K. Muth, D. V. Creel, S. A. Karns, and J. Wilkus, "Analysis of the relationship between economic measures and Salmonella testing results in young chicken slaughter establishments," Journal of Food Protection, vol. 75, no. 3, pp. 449-455, 2012.
[43] B. F. Brehm-Stecher, C. Young, L. A. Jaykus, and M. L. Tortorello, "Sample preparation: the forgotten beginning," Journal of Food Protection, vol. 72, no. 8, pp. 1774-1789, 2009.

[44] J. M. Eijkelkamp, H. J. M. Aarts, and H. J. van der FelsKlerx, "Suitability of rapid detection methods for Salmonella in poultry slaughterhouses," Food Analytical Methods, vol. 2, no. 1, pp. 1-13, 2009.

[45] R. S. Singer, A. E. Mayer, T. E. Hanson, and R. E. Isaacson, "Do microbial interactions and cultivation media decrease the accuracy of Salmonella surveillance systems and outbreak investigations?" Journal of Food Protection, vol. 72, no. 4, pp. 707-713, 2009.

[46] S. H. Park, M. Aydin, A. Khatiwara et al., "Current and emerging technologies for rapid detection and characterization of Salmonella in poultry and poultry products," Food Microbiology, vol. 38, pp. 250-262, 2014.

[47] T. W. Hennessy, L. H. Cheng, H. Kassenborg et al., "Egg consumption is the principal risk factor for sporadic Salmonella serotype Heidelberg infections: a case-control study in foodnet sites," Clinical Infectious Diseases, vol. 38, no. 3, pp. S237-S243, 2004.

[48] I. Gantois, R. Ducatelle, F. Pasmans et al., "Mechanisms of egg contamination by Salmonella Enteritidis," FEMS Microbiology Reviews, vol. 33, no. 4, pp. 718-738, 2009.

[49] F. Martelli and R. H. Davies, "Salmonella serovars isolated from table eggs: an overview," Food Research International, vol. 45, no. 2, pp. 745-754, 2012.

[50] S. C. Ricke, C. S. Dunkley, and J. A. Durant, "A review on development of novel strategies for controlling Salmonella Enteritidis colonization in laying hens: fiber-based molt diets," Poultry Science, vol. 92, no. 2, pp. 502-525, 2013.

[51] T. J. Humphrey, "Contamination of egg shell and contents with Salmonella enteritidis: a review," International Journal of Food Microbiology, vol. 21, no. 1-2, pp. 31-40, 1994.

[52] T. J. Humphrey, "Contamination of eggs and poultry meat with Salmonella enterica serovar Enteritidis," in Salmonella enterica Serovar Enteritidis in Humans and Animals-Epidemiology, Pathogenesis, and Control, A. M. Saeed, R. K. Gast, M. E. Potter, and P. G. Wall, Eds., chapter 18, pp. 183-192, Iowa State University Press, Ames, Iowa, USA, 1999.

[53] J. Guard-Petter, "The chicken, the egg and Salmonella enteritidis," Environmental Microbiology, vol. 3, no. 7, pp. 421-430, 2001.

[54] P. S. Holt, "Impact of induced molting on immunity and Salmonella enterica serovar Enteritidis infection in laying hens," in Salmonella enterica Serovar Enteritidis in Humans and Animals_Epidemiology, Pathogenesis, and Control, A. M. Saeed, R. K. Gast, M. E. Potter, and P. G. Wall, Eds., chapter 33, pp. 367375, Iowa State University Press, Ames, Iowa, USA, 1999.

[55] P. S. Holt, "Molting and Salmonella enterica serovar Enteritidis infection: the problem and some solutions," Poultry Science, vol. 82, no. 6, pp. 1008-1010, 2003.

[56] S. C. Ricke, "The gastrointestinal tract ecology of Salmonella Enteritidis colonization in molting hens," Poultry Science, vol. 82, no. 6, pp. 1003-1007, 2003.

[57] R. G. Board, "Review article: the course of microbial infection of the hen's egg," Journal of Applied Bacteriology, vol. 29, no. 2, pp. 319-341, 1966.

[58] W. A. Moats, "Egg washing—a review," Journal of Food Protection, vol. 41, pp. 919-925, 1978.

[59] K. Klippen, "Egg production and processing," Dairy, Food, and Environmental Sanitation, vol. 10, pp. 266-267, 1990. 
[60] J. L. Schoeni, K. A. Glass, J. L. McDermott, and A. C. L. Wong, "Growth and penetration of Salmonella enteritidis, Salmonella heidelberg and Salmonella typhimurium in eggs," International Journal of Food Microbiology, vol. 24, no. 3, pp. 385-396, 1995.

[61] M. E. Berrang, N. A. Cox, J. F. Frank, and R. J. Buhr, "Bacterial penetration of the eggshell and shell membranes of the chicken hatching egg: a review," Journal of Applied Poultry Research, vol. 8, no. 4, pp. 499-504, 1999.

[62] N. A. Cox, M. E. Berrang, and J. A. Cason, "Salmonella penetration of egg shells and proliferation in broiler hatching eggsa review," Poultry Science, vol. 79, no. 11, pp. 1571-1574, 2000.

[63] M. L. Hutchison, J. Gittins, A. Walker, A. Moore, C. Burton, and N. Sparks, "Washing table eggs: a review of the scientific and engineering issues," World's Poultry Science Journal, vol. 59, no. 2, pp. 233-248, 2003.

[64] P. Curtis, "Microbiological challenges of poultry egg production in the US," World's Poultry Science Journal, vol. 63, no. 2, pp. 301307, 2007.

[65] M. Rossi, Y. Nys, M. Anton et al., "Developments in understanding and assessment of egg and egg product quality over the last century," World's Poultry Science Journal, vol. 69, no. 2, pp. 414429, 2013.

[66] W. Messens, K. Grijspeerdt, and L. Herman, "Eggshell penetration by Salmonella: a review," World's Poultry Science Journal, vol. 61, no. 1, pp. 71-86, 2005.

[67] J.-W. Kim and M. F. Slavik, "Changes in eggshell surface microstructure after washing with cetylpyridinium chloride or trisodium phosphate," Journal of Food Protection, vol. 59, no. 8, pp. 859-863, 1996.

[68] E. C. D. Todd, "Risk assessment of use of cracked eggs in Canada," International Journal of Food Microbiology, vol. 30, no. 1-2, pp. 125-143, 1996.

[69] Y. Hara-Kudo, Y. Sakakibara, H. Konuma, T. Sawada, and S. Kumagai, "Laying season and egg shell cracks on the growth of Salmonella Enteritidis in the egg albumen during storage," Journal of Food Protection, vol. 64, no. 8, pp. 1134-1137, 2001.

[70] M. Rose-Martel, J. Du, and M. T. Hincke, "Proteomic analysis provides new insight into the chicken eggshell cuticle," Journal of Proteomics, vol. 75, no. 9, pp. 2697-2706, 2012.

[71] J. A. Kinner and W. A. Moats, "Effect of temperature, pH, and detergent on survival of bacteria associated with shell eggs," Poultry Science, vol. 60, pp. 761-767, 1981.

[72] R. A. Holley and M. Proulx, "Use of egg washwater pH to prevent survival of Salmonella at moderate temperatures," Poultry Science, vol. 65, no. 5, pp. 922-928, 1986.

[73] F. M. Bartlett, J. M. Laird, C. L. Addison, and R. C. McKellar, "The analysis of egg wash water for the rapid assessment of microbiological quality," Poultry Science, vol. 72, no. 8, pp. 15841591, 1993.

[74] K. Leclair, H. Heggart, M. Oggel, F. M. Bartlett, and R. C. McKellar, "Modelling the inactivation of Listeria monocytogenes and Salmonella typhimurium in simulated egg wash water," Food Microbiology, vol. 11, no. 4, pp. 345-354, 1994.

[75] M. L. Hutchison, J. Gittins, A. Walker et al., "An assessment of the microbiological risks involved with egg washing under commercial conditions," Journal of Food Protection, vol. 67, no. 1, pp. 4-11, 2004.

[76] F. T. Jones, D. V. Rives, and J. B. Carey, "Salmonella contamination in commercial eggs and an egg production facility," Poultry Science, vol. 74, no. 4, pp. 753-757, 1995.
[77] R. H. Davies and M. Breslin, "Investigation of Salmonella contamination and disinfection in farm egg-packing plants," Journal of Applied Microbiology, vol. 94, no. 2, pp. 191-196, 2003.

[78] M. T. Musgrove, J. D. Shaw, and M. A. Harrison, "Salmonella collected from nest run cart shelves in commercial shell egg processing facilities," Poultry Science, vol. 91, no. 9, pp. 23862389, 2012.

[79] D. R. Jones, J. K. Northcutt, M. T. Musgrove et al., "Survey of shell egg processing plant sanitation programs: effects on egg contact surfaces," Journal of Food Protection, vol. 66, no. 8, pp. 1486-1489, 2003.

[80] M. T. Musgrove, D. R. Jones, J. K. Northcutt et al., "Survey of shell egg processing plant sanitation programs: effects on nonegg-contact surfaces," Journal of Food Protection, vol. 67, no. 12, pp. 2801-2804, 2004.

[81] M. T. Musgrove, D. R. Jones, J. D. Shaw, M. Sheppard, and M. A. Harrison, "Enterobacteriaceae and related organisms isolated from nest run cart shelves in commercial shell egg processing facilities," Poultry Science, vol. 88, no. 10, pp. 2113-2117, 2009.

[82] S. Singh, A. S. Yadav, S. M. Singh, and P. Bharti, "Prevalence of Salmonella in chicken eggs collected from poultry farms and marketing channels and their antimicrobial resistance," Food Research International, vol. 43, no. 8, pp. 2027-2030, 2010.

[83] T. Suresh, A. A. M. Hatha, D. Sreenivasan, N. Sangeetha, and P. Lashmanaperumalsamy, "Prevalence and antimicrobial resistance of Salmonella enteritidis and other Salmonellas in the eggs and egg-storing trays from retails markets of Coimbatore, South India," Food Microbiology, vol. 23, no. 3, pp. 294-299, 2006.

[84] F. Utrarachkij, S. Pornraungwong, K. Siripanichgon, C. Nakajima, Y. Suzuki, and O. Suthienkul, "Possible horizontal transmission of Salmonella via reusable egg trays in Thailand," International Journal of Food Microbiology, vol. 154, no. 1-2, pp. 73-78, 2012.

[85] P. S. Holt, R. H. Davies, J. Dewulf et al., "The impact of different housing systems on egg safety and quality," Poultry Science, vol. 90, no. 1, pp. 251-262, 2011.

[86] J. F. Hannah, J. L. Wilson, N. A. Cox et al., "Comparison of shell bacteria from unwashed and washed table eggs harvested from caged laying hens and cage-free floor-housed laying hens," Poultry Science, vol. 90, no. 7, pp. 1586-1593, 2011.

[87] D. R. Jones, K. E. Anderson, and M. T. Musgrove, "Comparison of environmental and egg microbiology associated with conventional and free-range laying hen management," Poultry Science, vol. 90, no. 9, pp. 2063-2068, 2011.

[88] S. Vandeplas, R. D. Dauphin, Y. Beckers, P. Thonart, and A. Théwis, "Salmonella in chicken: current and developing strategies to reduce contamination at farm level," Journal of Food Protection, vol. 73, no. 4, pp. 774-785, 2010.

[89] V. V. Volkova, R. H. Bailey, M. L. Rybolt et al., "Inter-relationships of Salmonella status of flock and grow-out environment at sequential segments in broiler production and processing," Zoonoses and Public Health, vol. 57, no. 7-8, pp. 463-475, 2010.

[90] F. T. Jones, R. C. Axtell, D. V. Rives et al., "A survey of Salmonella contamination in modern broiler production," Journal of Food Protection, vol. 54, pp. 502-507, 1991.

[91] J. T. Singer, H. M. Opitz, M. Gershman, M. M. Hall, I. G. Muniz, and S. V. Rao, "Molecular characterization of Salmonella enteritidis isolates from Maine poultry and poultry farm environments," Avian Diseases, vol. 36, no. 2, pp. 324-333, 1992.

[92] E. J. van Loo, W. Alali, and S. C. Ricke, "Food safety and organic meats," Annual Review of Food Science and Technology, vol. 3, no. 1, pp. 205-225, 2012. 
[93] E. J. van Loo, S. N. Melendez, I. B. Hanning-Jarquin, and S. C. Ricke, "Foodborne pathogen occurrence in organically raised poultry," in Organic Meat Production and Processing, S. C. Ricke, E. J. van Loo, M. G. Johnson, and C. A. O’Bryan, Eds., chapter 19, pp. 315-328, Wiley, New York, NY, USA, 2012.

[94] M. Nakamura, M. Takagi, T. Takahashi, S. Suzuki, S. Sato, and K. Takehara, "The effect of the flow of air on horizontal transmission of Salmonella enteritidis in chickens," Avian Diseases, vol. 41, no. 2, pp. 354-360, 1997.

[95] Y. M. Kwon, C. L. Woodward, S. D. Pillai et al., "Litter and aerosol sampling of chicken houses for rapid detection of Salmonella typhimurium contamination using gene amplification," Journal of Industrial Microbiology and Biotechnology, vol. 24, no. 6, pp. 379-382, 2000.

[96] Y. M. Kwon, C. L. Woodward, D. E. Corrier, J. A. Byrd, S. D. Pillai, and S. C. Ricke, "Recovery of a marker strain of Salmonella typhimurium in litter and aerosols from isolation rooms containing infected chickens," Journal of Environmental Science and Health B: Pesticides, Food Contaminants, and Agricultural Wastes, vol. 35, no. 4, pp. 517-525, 2000.

[97] B. W. Mitchell, R. J. Buhr, M. E. Berrang, J. S. Bailey, and N. A. Cox, "Reducing airborne pathogens, dust and Salmonella transmission in experimental hatching cabinets using an electrostatic space charge system," Poultry Science, vol. 81, no. 1, pp. 49-55, 2002.

[98] R. K. Gast, B. W. Mitchell, and P. S. Holt, "Evaluation of culture media for detecting airborne Salmonella enteritidis collected with an electrostatic sampling device from the environment of experimentally infected laying hens," Poultry Science, vol. 83, no. 7, pp. 1106-1111, 2004.

[99] J. E. Williams and S. T. Benson, "Survival of Salmonella typhimurium in poultry feed and litter at three temperatures," Avian Diseases, vol. 22, no. 4, pp. 742-747, 1978.

[100] B. J. Juven, N. A. Cox, J. S. Bailey, J. E. Thomson, O. W. Charles, and J. V. Shutze, "Survival of Salmonella in dry food and feed," Journal of Food Protection, vol. 47, no. 6, pp. 445-448, 1984.

[101] S. D. Ha, K. G. Maciorowski, Y. M. Kwon, F. T. Jones, and S. C. Ricke, "Survivability of indigenous microflora and a Salmonella typhimurium marker strain in poultry mash treated with buffered propionic acid," Animal Feed Science and Technology, vol. 75, no. 2, pp. 145-155, 1998.

[102] S. D. Ha, K. G. Maciorowski, Y. M. Kwon, F. T. Jones, and S. C. Ricke, "Indigenous feed microflora and Salmonella typhimurium marker strain survival in poultry mash diets containing varying levels of protein," Animal Feed Science and Technology, vol. 76, no. 1-2, pp. 23-33, 1998.

[103] S. Y. Park, S. G. Birkhold, L. F. Kubena, D. J. Nisbet, and S. C. Ricke, "Survival of a Salmonella typhimurium poultry marker strain added as a dry inoculum to zinc and sodium organic acid amended feeds," Journal of Food Safety, vol. 23, no. 4, pp. 263274, 2003.

[104] A. Petkar, W. Q. Alali, M. A. Harrison, and L. R. Beuchat, "Survival of Salmonella in organic and conventional broiler feed as affected by temperature and water activity," Agriculture, Food and Analytical Bacteriology, vol. 1, pp. 175-185, 2011.

[105] R. Jarquin, I. Hanning, S. Ahn, and S. C. Ricke, "Development of rapid detection and genetic characterization of Salmonella in poultry breeder feeds," Sensors, vol. 9, no. 7, pp. 5308-5323, 2009.

[106] M. E. Patrick, P. M. Adcock, T. M. Gomez et al., "Salmonella Enteritidis infections, United States, 1985-1999," Emerging Infectious Diseases, vol. 10, no. 1, pp. 1-7, 2004.
[107] C. R. Braden, "Salmonella enterica serotype Enteritidis and eggs: a national epidemic in the United States," Clinical Infectious Diseases, vol. 43, no. 4, pp. 512-517, 2006.

[108] M. E. St. Louis, D. L. Morse, M. E. Potter et al., "The emergence of grade A eggs as a major source of Salmonella enteritidis infections: new implications for the control of salmonellosis," The Journal of the American Medical Association, vol. 259, no. 14, pp. 2103-2107, 1988.

[109] T. A. Cogan and T. J. Humphrey, "The rise and fall of Salmonella Enteritidis in the UK," Journal of Applied Microbiology, vol. 94, pp. 114S-119S, 2003.

[110] D. J. Henzler and H. M. Opitz, "The role of mice in the epizootiology of Salmonella enteritidis infection on chicken layer farms," Avian Diseases, vol. 36, no. 3, pp. 625-631, 1992.

[111] N. C. Hinkle and L. A. Hickle, "California caged layer pest management evaluation," Journal of Applied Poultry Research, vol. 8, no. 3, pp. 327-338, 1999.

[112] A. R. Olsen and T. S. Hammack, "Isolation of Salmonella spp. from the housefly, Musca domestica L., and the dump fly, Hydrotaea aenescens (Wiedemann) (Diptera: Muscidae), at caged-layer houses," Journal of Food Protection, vol. 63, no. 7, pp. 958-960, 2000.

[113] R. Davies and M. Breslin, "Environmental contamination and detection of Salmonella enterica serovar Enteritidis in laying flocks," Veterinary Record, vol. 149, no. 23, pp. 699-704, 2001.

[114] K. de Reu, W. Messens, M. Heyndrickx, T. B. Rodenburg, M. Uyttendaele, and L. Herman, "Bacterial contamination of table eggs and the influence of housing systems," World's Poultry Science Journal, vol. 64, no. 1, pp. 5-19, 2008.

[115] R. Lapuz, H. Tani, K. Sasai, K. Shirota, H. Katoh, and E. Baba, "The role of roof rats (Rattus rattus) in the spread of Salmonella Enteritidis and S. Infantis contamination in layer farms in eastern Japan," Epidemiology and Infection, vol. 136, no. 9, pp. $1235-1243,2008$.

[116] F. T. Jones and K. E. Richardson, "Salmonella in commercially manufactured feeds," Poultry Science, vol. 83, no. 3, pp. 384-391, 2004.

[117] K. G. Maciorowski, P. Herrera, M. M. Kundinger, and S. C. Ricke, "Animal feed production and contamination by foodborne Salmonella," Journal of Consumer Protection and Food Safety, vol. 1, no. 3, pp. 197-209, 2006.

[118] K. G. Maciorowski, P. Herrera, F. T. Jones, S. D. Pillai, and S. C. Ricke, "Effects on poultry and livestock of feed contamination with bacteria and fungi," Animal Feed Science and Technology, vol. 133, no. 1-2, pp. 109-136, 2007.

[119] S. C. Ricke, "Ensuring the safety of poultry feed," in Food Safety Control in the Poultry Industry, G. C. Mead, Ed., chapter 7, pp. 174-194, Woodhead Publishing, Cambridge, UK, 2005.

[120] R. H. Davies and A. D. Wales, "Investigations into Salmonella contamination in poultry feedmills in the United Kingdom," Journal of Applied Microbiology, vol. 109, no. 4, pp. 1430-1440, 2010.

[121] B. Ge, P. C. Lafon, P. J. Carter et al., "Retrospective analysis of Salmonella, Campylobacter, Escherichia coli, and Enterococcus in animal feed ingredients," Foodborne Pathogens and Disease, vol. 10, no. 8, pp. 684-691, 2013.

[122] S. C. Ricke, S. D. Pillai, R. A. Norton, K. G. Maciorowski, and F. T. Jones, "Applicability of rapid methods for detection of Salmonella spp. in poultry feeds: a review," Journal of Rapid Methods and Automation in Microbiology, vol. 6, no. 4, pp. 239258, 1998. 
[123] K. G. Maciorowski, S. D. Pillai, and S. C. Ricke, "Efficacy of a commercial polymerase chain reaction-based assay for detection of Salmonella spp. in animal feeds," Journal of Applied Microbiology, vol. 89, no. 4, pp. 710-718, 2000.

[124] K. G. Maciorowski, P. Herrera, F. T. Jones, S. D. Pillai, and S. C. Ricke, "Cultural and immunological detection methods for Salmonella spp. in animal feeds-a review," Veterinary Research Communications, vol. 30, no. 2, pp. 127-137, 2006.

[125] K. G. Maciorowski, S. D. Pillai, F. T. Jones, and S. C. Ricke, "Polymerase chain reaction detection of foodborne Salmonella spp. in animal feeds," Critical Reviews in Microbiology, vol. 31, no. 1, pp. 45-53, 2005.

[126] S. H. Park, R. Jarquin, I. Hanning, G. Almeida, and S. C. Ricke, "Detection of Salmonella spp. survival and virulence in poultry feed by targeting the hilA gene," Journal of Applied Microbiology, vol. 111, no. 2, pp. 426-432, 2011.

[127] M. C. Soria, M. A. Soria, D. J. Bueno, and J. L. Colazo, "A comparative study of culture methods and polymerase chain reaction assay for Salmonella detection in poultry feed," Poultry Science, vol. 90, no. 11, pp. 2606-2618, 2011.

[128] M. O. North and D. D. Bell, Commercial Chicken Production Manual, Chapman and Hall, New York, NY, USA, 4th edition, 1990.

[129] D. D. Bell, "Historical and current molting practices in the U.S. table egg industry," Poultry Science, vol. 82, no. 6, pp. 965-970, 2003.

[130] W. D. Berry, "The physiology of induced molting," Poultry Science, vol. 82, no. 6, pp. 971-980, 2003.

[131] S. Y. Park, W. K. Kim, S. G. Birkhold, L. F. Kubena, D. J. Nisbet, and S. C. Ricke, "Induced moulting issues and alternative dietary strategies for the egg industry in the United States," World's Poultry Science Journal, vol. 60, no. 2, pp. 196-261, 2004.

[132] S. C. Ricke, C. S. Dunkley, J. L. McReynolds, K. D. Dunkley, and D. J. Nisbet, "Molting in laying hens and Salmonella infection," in Dynamics in Animal Nutrition, P. J. van der Aar and J. Doppenberg, Eds., pp. 135-146, Wageningen Academic Publishers, Wageningen, The Netherlands, 2010.

[133] W. J. Kuenzel, "Neurobiology of molt in avian species," Poultry Science, vol. 82, no. 6, pp. 981-991, 2003.

[134] W. K. Kim, S. A. Bloomfield, T. Sugiyama, and S. C. Ricke, "Concepts and methods for understanding bone metabolism in laying hens," World's Poultry Science Journal, vol. 68, no. 1, pp. 71-82, 2012.

[135] C. S. Dunkley, J. L. McReynolds, K. D. Dunkley, L. F. Kubena, D. J. Nisbet, and S. C. Ricke, "Molting in Salmonella Enteritidischallenged laying hens fed alfalfa crumbles. III. Blood plasma metabolite response," Poultry Science, vol. 86, no. 12, pp. 24922501, 2007.

[136] C. S. Dunkley, J. L. McReynolds, K. D. Dunkley et al., "Molting in Salmonella Enteritidis-challenged laying hens fed alfalfa crumbles. IV. Immune and stress protein response," Poultry Science, vol. 86, no. 12, pp. 2502-2508, 2007.

[137] M. Yousaf and A. S. Chaudhry, "History, changing scenarios and future strategies to induce moulting in laying hens," World's Poultry Science Journal, vol. 64, no. 1, pp. 65-75, 2008.

[138] J. A. Durant, D. E. Corrier, J. A. Byrd, L. H. Stanker, and S. C. Ricke, "Feed deprivation affects crop environment and modulates Salmonella enteritidis colonization and invasion of leghorn hens," Applied and Environmental Microbiology, vol. 65, no. 5, pp. 1919-1923, 1999.
[139] K. D. Dunkley, J. L. McReynolds, M. E. Hume et al., "Molting in Salmonella Enteritidis-challenged laying hens fed alfalfa crumbles. I. Salmonella Enteritidis colonization and virulence gene hilA response," Poultry Science, vol. 86, no. 8, pp. 1633-1639, 2007.

[140] K. D. Dunkley, J. L. McReynolds, M. E. Hume et al., "Molting in Salmonella Enteritidis-challenged laying hens fed alfalfa crumbles. II. Fermentation and microbial ecology response," Poultry Science, vol. 86, no. 10, pp. 2101-2109, 2007.

[141] A. M. McNamara, "Generic HACCP application in broiler slaughter and processing," Journal of Food Protection, vol. 60, no. 5, pp. 579-604, 1997.

[142] A. M. Lammerding and A. Fazil, "Hazard identification and exposure assessment for microbial food safety risk assessment," International Journal of Food Microbiology, vol. 58, no. 3, pp. 147-157, 2000.

[143] Y. M. Kwon and S. C. Ricke, "Induction of acid resistance of Salmonella typhimurium by exposure to short-chain fatty acids," Applied and Environmental Microbiology, vol. 64, no. 9, pp. 3458-3463, 1998.

[144] S. C. Ricke, "Perspectives on the use of organic acids and short chain fatty acids as antimicrobials," Poultry Science, vol. 82, no. 4, pp. 632-639, 2003.

[145] Y. M. Kwon, S. Y. Park, S. G. Birkhold, and S. C. Ricke, "Induction of resistance of Salmonella typhimurium to environmental stresses by exposure to short-chain fatty acids," Journal of Food Science, vol. 65, no. 6, pp. 1037-1040, 2000.

[146] C. A. O’Bryan, P. G. Crandall, and S. C. Ricke, "Organic poultry pathogen control from farm to fork," Foodborne Pathogens and Disease, vol. 5, no. 6, pp. 709-720, 2008.

[147] S. A. Sirsat, A. Muthaiyan, and S. C. Ricke, "Antimicrobials for foodborne pathogen reduction in organic and natural poultry production," Journal of Applied Poultry Research, vol. 18, no. 2, pp. 379-388, 2009.

[148] L. Leistner, "Food preservation by combined methods," Food Research International, vol. 25, no. 2, pp. 151-158, 1992.

[149] S. C. Ricke, M. M. Kundinger, D. R. Miller, and J. T. Keeton, "Alternatives to antibiotics: chemical and physical antimicrobial interventions and foodborne pathogen response," Poultry Science, vol. 84, no. 4, pp. 667-675, 2005.

[150] S. A. Sirsat, A. Muthaiyan, S. E. Dowd, Y. M. Kwon, and S. C. Ricke, "The potential for application of foodborne Salmonella gene expression profiling assays in postharvest poultry processing," in Perspectives on Food Safety Issues of Food Animal Derived Foods, S. C. Ricke and F. T. Jones, Eds., pp. 195-222, University of Arkansas Press, Fayetteville, Ark, USA, 2010.

[151] S. R. Milillo and S. C. Ricke, "Synergistic reduction of Salmonella in a model raw chicken media using a combined thermal and acidified organic acid salt intervention treatment," Journal of Food Science, vol. 75, no. 2, pp. M121-M125, 2010.

[152] S. R. Milillo, E. Martin, A. Muthaiyan, and S. C. Ricke, "Immediate reduction of Salmonella enterica serotype Typhimurium following exposure to multiple-hurdle treatments with heated, acidified organic acid salt solutions," Applied and Environmental Microbiology, vol. 77, pp. 3765-3772, 2011.

[153] V. I. Chalova, O. Hernández-Hernández, A. Muthaiyan et al., "Growth and transcriptional response of Salmonella Typhimurium LT2 to glucose-lysine-based Maillard reaction products generated under low water activity conditions," Food Research International, vol. 45, no. 2, pp. 1044-1053, 2012.

[154] S. A. Sirsat, A. Muthaiyan, and S. C. Ricke, "Optimization of the RNA extraction method for transcriptome studies of Salmonella 
inoculated on commercial raw chicken breast samples," $B M C$ Research Notes, vol. 4, article 60, 2011.

[155] J. C. Ayres, A. A. Kraft, R. G. Board, G. S. Torrey, and S. S. Rizk, "Sanitation practices in egg handling and breaking plants and the application of several disinfectants for sanitizing eggs," Journal of Applied Bacteriology, vol. 30, no. 1, pp. 106-116, 1967.

[156] M. E. Berrang, N. A. Cox, J. F. Frank, R. J. Buhr, and J. S. Bailey, "Hatching egg sanitization for prevention or reduction of human enteropathogens: a review," Journal of Applied Poultry Research, vol. 9, no. 2, pp. 279-284, 2000.

[157] P. H. Patterson, S. C. Ricke, M. L. Sunde, and D. M. Schaefer, "Hatching eggs sanitized with chlorine dioxide foam: egg hatchability and bactericidal properties," Avian Diseases, vol. 34, no. 1, pp. 1-6, 1990.

[158] N. A. Cox, J. S. Bailey, and M. E. Berrang, "Bactericidal treatment of hatching eggs I. Chemical immersion treatments and Salmonella," Journal of Applied Poultry Research, vol. 7, no. 4, pp. 347-350, 1998.

[159] N. A. Cox, J. M. Mauldin, R. Kumararaj, and M. T. Musgrove, "Ability of hydrogen peroxide and timsen to eliminate artificially inoculated Salmonella from fertile broiler eggs," Journal of Applied Poultry Research, vol. 11, no. 3, pp. 266-269, 2002.

[160] N. A. Cox, L. J. Richardson, R. J. Buhr, M. T. Musgrove, M. E. Berrang, and W. Bright, "Bactericidal effect of several chemicals on hatching eggs inoculated with Salmonella serovar Typhimurium," Journal of Applied Poultry Research, vol. 16, no. 4, pp. 623-627, 2007.

[161] F.-L. Kuo, J. B. Carey, S. C. Ricke, and S. D. Ha, "Peroxidase catalyzed chemical dip, egg shell surface contamination, and hatching," Journal of Applied Poultry Research, vol. 5, no. 1, pp. 6-13, 1996.

[162] F.-L. Kuo, Y. M. Kwon, J. B. Carey, B. M. Hargis, D. P. Krieg, and S. C. Ricke, "Reduction of Salmonella contamination on chicken egg shells by a peroxidase-catalyzed sanitizer," Journal of Food Science, vol. 62, no. 4, pp. 873-884, 1997.

[163] Y. M. Kwon, D. P. Krieg, F.-L. Kuo, J. B. Carey, and S. C. Ricke, "Biocidal activity of a peroxidase-catalyzed sanitizer against selected bacteria on inert carriers and egg shells," Journal of Food Safety, vol. 16, no. 4, pp. 243-254, 1996.

[164] S. R. McKee, Y. M. Kwon, J. B. Carey, A. R. Sams, and S. C. Ricke, "Comparison of a peroxidase-catalyzed sanitizer with other egg sanitizers using a laboratory-scale sprayer," Journal of Food Safety, vol. 18, no. 3, pp. 173-183, 1998.

[165] K. D. Knape, J. B. Carey, R. P. Burgess, Y. M. Kwon, and S. C. Ricke, "Comparison of chlorine with an iodine-based compound on eggshell surface microbial populations in a commercial egg washer," Journal of Food Safety, vol. 19, no. 3, pp. 185-194, 1999.

[166] K. D. Knape, J. B. Carey, and S. C. Ricke, "Comparison of chlorine with an iodine based compound on eggshell surface Salmonella typhimurium and S. enteritidis populations in a commercial egg washer," Journal of Environmental Science and Health B, vol. 36, pp. 219-227, 2001.

[167] S. M. Russell, "The effect of electrolyzed oxidative water applied using electrostatic spraying on pathogenic and indicator bacteria on the surface of eggs," Poultry Science, vol. 82, no. 1, pp. 158-162, 2003.

[168] C.-M. Park, Y.-C. Hung, C.-S. Lin, and R. E. Brackett, "Efficacy of electrolyzed water in inactivating Salmonella Enteritidis and Listeria monocytogenes on shell eggs," Journal of Food Protection, vol. 68 , no. 5, pp. 986-990, 2005.
[169] W. Cao, Z. W. Zhu, Z. X. Shi, C. Y. Wang, and B. M. Li, "Efficiency of slightly acidic electrolyzed water for inactivation of Salmonella Enteritidis and its contaminated shell eggs," International Journal of Food Microbiology, vol. 130, no. 2, pp. 88-93, 2009.

[170] C. Jo, D. U. Ahn, X. D. Liu, K. H. Kim, and K.-C. Nam, "Effects of chitosan coating and storage with dry ice on the freshness and quality of eggs," Poultry Science, vol. 90, no. 2, pp. 467-472, 2011.

[171] S. Leleu, L. Herman, M. Heyndrickx et al., "Effects on Salmonella shell contamination and trans-shell penetration of coating hens' eggs with chitosan," International Journal of Food Microbiology, vol. 145, no. 1, pp. 43-48, 2011.

[172] I. Upadhyaya, A. Upadhyay, A. Kollanoor-Johny et al., "Rapid inactivation of Salmonella Enteritidis on shell eggs by plantderived antimicrobials," Poultry Science, vol. 92, no. 12, pp. 3228-3235, 2013.

[173] T. A. Scott, "The effect of UV-light and air filtering system on embryo viability and microorganism load on the egg shell," The Journal of Applied Poultry Research, vol. 2, pp. 19-25, 1993.

[174] M. E. Berrang, N. A. Cox, J. S. Bailey, and R. J. Buhr, "Efficacy of ultraviolet light for elimination of Salmonella on broiler hatching eggs," The Journal of Applied Poultry Research, vol. 4, pp. 422-429, 1995.

[175] F.-L. Kuo, J. B. Carey, and S. C. Ricke, "UV irradiation of shell eggs: effect on populations of aerobes, molds, and inoculated Salmonella typhimurium," Journal of Food Protection, vol. 60, no. 6, pp. 639-643, 1997.

[176] F.-L. Kuo, S. C. Ricke, and J. B. Carey, "Shell egg sanitation: UV radiation and egg rotation to effectively reduce populations of aerobes, yeasts, and molds," Journal of Food Protection, vol. 60, no. 6, pp. 694-697, 1997.

[177] C. Chavez, K. D. Knape, C. D. Coufal, and J. B. Carey, "Reduction of eggshell aerobic plate counts by ultraviolet irradiation," Poultry Science, vol. 81, no. 8, pp. 1132-1135, 2002.

[178] C. D. Coufal, C. Chavez, K. D. Knape, and J. B. Carey, "Evaluation of a method of ultraviolet light sanitation of broiler hatching eggs," Poultry Science, vol. 82, no. 5, pp. 754-759, 2003.

[179] L. A. Rodriguez-Romo and A. E. Yousef, "Inactivation of Salmonella enterica serovar Enteritidis on shell eggs by ozone and UV radiation," Journal of Food Protection, vol. 68, no. 4, pp. 711-717, 2005.

[180] L. Ragni, A. Berardinelli, L. Vannini et al., "Non-thermal atmospheric gas plasma device for surface decontamination of shell eggs," Journal of Food Engineering, vol. 100, no. 1, pp. 125-132, 2010.

[181] C. Borie, I. Albala, P. Sànchez et al., "Bacteriophage treatment reduces Salmonella colonization of infected chickens," Avian Diseases, vol. 52, no. 1, pp. 64-67, 2008.

[182] J. Robeson, M. Valencia, J. Retamales, and C. Borie, "Stability inside hen eggs of a Salmonella enterica serovar Enteritidis bacteriophage," Electronic Journal of Biotechnology, vol. 14, no. 4, 2011.

[183] C. Bardina, D. A. Spricigo, P. Cortés, and M. Llagostera, "Significance of the bacteriophage treatment schedule in reducing Salmonella colonization of poultry," Applied and Environmental Microbiology, vol. 78, no. 18, pp. 6600-6607, 2012.

[184] S. C. Ricke, P. Hererra, and D. Biswas, "Bacteriophages for potential food safety applications in organic meat production," in Organic Meat Production and Processing, S. C. Ricke, E. J. van Loo, M. G. Johnson, and C. A. O'Bryan, Eds., chapter 23, pp. 407-424, Wiley Scientific/IFT, New York, NY, USA, 2012. 
[185] A. Henriques, R. Sereno, and A. Almeida, "Reducing Salmonella horizontal transmission during egg incubation by phage therapy," Foodborne Pathogens and Disease, vol. 10, no. 8, pp. 718722, 2013

[186] D. A. Spricigo, C. Bardina, P. Cortés, and M. Llagostera, "Use of a bacteriophage cocktail to control Salmonella in food and the food industry," International Journal of Food Microbiology, vol. 165, no. 2, pp. 169-174, 2013.

[187] Y. M. Kwon, L. F. Kubena, D. J. Nisbet, and S. C. Ricke, "Isolation of Salmonella typhimurium Tn5 mutants defective for survival on egg shell surface using transposon footprinting," Journal of Environmental Science and Health Part B: Pesticides, Food Contaminants, and Agricultural Wastes, vol. 38, no. 1, pp. 103109, 2003.

[188] S. Lu, P. B. Killoran, and L. W. Riley, "Association of Salmonella enterica serovar Enteritidis YafD with resistance to chicken egg albumen," Infection and Immunity, vol. 71, no. 12, pp. 6734-6741, 2003.

[189] D. H. Shah, X. Zhou, H.-Y. Kim, D. R. Call, and J. Guard, "Transposon mutagenesis of Salmonella enterica serovar Enteritidis identifies genes that contribute to invasiveness in human and chicken cells and survival in egg albumen," Infection and Immunity, vol. 80, no. 12, pp. 4203-4215, 2012.

[190] R. C. Whiting and R. L. Buchanan, "Development of a quantitative risk assessment model for Salmonella enteritidis in pasteurized liquid eggs," International Journal of Food Microbiology, vol. 36, no. 2-3, pp. 111-125, 1997.

[191] C. M. Schroeder, H. K. Latimer, W. D. Schlosser et al., "Overview and summary of the food safety and inspection service risk assessment for Salmonella Enteritidis in shell eggs, October 2005," Foodborne Pathogens and Disease, vol. 3, no. 4, pp. 403412, 2006.

[192] K. C. Milner and M. F. Shaffer, "Bacteriologic studies of experimental Salmonella infections in chicks," The Journal of Infectious Diseases, vol. 90, pp. 81-85, 1952.

[193] J. H. Schleifer, B. J. Juven, C. W. Beard, and N. A. Cox, "The susceptibility of chicks to Salmonella montevideo in artificially contaminated poultry feed," Avian Diseases, vol. 28, no. 2, pp. 497-503, 1984.

[194] J. S. Bailey, "Integrated colonization control of Salmonella in poultry," Poultry Science, vol. 67, no. 6, pp. 928-932, 1988.

[195] S. C. Ricke, C. L. Woodward, Y. M. Kwon, L. F. Kubena, and D. J. Nisbet, "Limiting avian gastrointestinal tract Salmonella colonization by cecal anaerobic bacteria and a potential role for methanogens," in Pre-Harvest and Post-Harvest Food Safety: Contemporary Issues and Future Directions, R. C. Beier, S. D. Pillai, T. D. Phillips, and R. L. Ziprin, Eds., chapter 11, pp. 141150, Blackwell Publishing Professional, Ames, Iowa, USA, 2004.

[196] S. Leeson and M. Marcotte, "Irradiation of poultry feed I. Microbial status and bird response," World's Poultry Science Journal, vol. 49, no. 1, pp. 19-33, 1993.

[197] A. D. Wales, V. M. Allen, and R. H. Davies, "Chemical treatment of animal feed and water for the control of Salmonella," Foodborne Pathogens and Disease, vol. 7, no. 1, pp. 3-15, 2010.

[198] F. T. Jones, "A review of practical Salmonella control measures in animal feed," Journal of Applied Poultry Research, vol. 20, no. 1, pp. 102-113, 2011.

[199] E. Nurmi and M. Rantala, "New aspects of Salmonella infection in broiler production," Nature, vol. 241, no. 5386, pp. 210-211, 1973.

[200] J. S. Bailey, "Factors affecting microbial competitive exclusion in poultry," Food Technology, vol. 41, pp. 88-92, 1987.
[201] D. J. Nisbet, S. C. Ricke, C. M. Scanlan, D. E. Corrier, A. G. Hollister, and J. R. Deloach, "Inoculation of broiler chicks with a continuous-flow derived bacterial culture facilitates early cecal bacterial colonization and increases resistance to Salmonella typhimurium," Journal of Food Protection, vol. 57, no. 1, pp. 12-15, 1994.

[202] D. E. Corrier, D. J. Nisbet, C. M. Scanlan, G. Tellez, B. M. Hargis, and J. R. Deloach, "Inhibition of Salmonella enteritidis cecal and organ colonization in leghorn chicks by a defined culture of cecal bacteria and dietary lactose," Journal of Food Protection, vol. 57, no. 5, pp. 377-381, 1994.

[203] D. E. Corrier, D. J. Nisbet, C. M. Scanlan, A. G. Hollister, and J. R. Deloach, "Control of Salmonella typhimurium colonization in broiler chicks with a continuous-flow characterized mixed culture of cecal bacteria," Poultry Science, vol. 74, no. 6, pp. 916924, 1995.

[204] S. C. Ricke and S. D. Pillai, "Conventional and molecular methods for understanding probiotic bacteria functionality in gastrointestinal tracts," Critical Reviews in Microbiology, vol. 25, no. 1, pp. 19-38, 1999.

[205] G. C. Mead, "Prospects for "competitive exclusion" treatment to control Salmonellas and other foodborne pathogens in poultry," The Veterinary Journal, vol. 159, no. 2, pp. 111-123, 2000.

[206] D. Nisbet, "Defined competitive exclusion cultures in the prevention of enteropathogen colonisation in poultry and swine," Antonie van Leeuwenhoek, vol. 81, no. 1-4, pp. 481-486, 2002.

[207] M. E. Hume, "Historic perspective: prebiotics, probiotics, and other alternatives to antibiotics," Poultry Science, vol. 90, no. 11, pp. 2663-2669, 2011.

[208] G. R. Siragusa and S. C. Ricke, "Probiotics as pathogen control agents for organic meat production," in Organic Meat Production and Processing, S. C. Ricke, E. J. van Loo, M. G. Johnson, and C. A. O'Bryan, Eds., chapter 20, pp. 331-349, Wiley Scientific/IFT, New York, NY, USA, 2012.

[209] J. A. Patterson and K. M. Burkholder, "Application of prebiotics and probiotics in poultry production," Poultry Science, vol. 82, no. 4, pp. 627-631, 2003.

[210] L. Revolledo, A. J. P. Ferreira, and G. C. Mead, "Prospects in Salmonella control: competitive exclusion, probiotics, and enhancement of avian intestinal immunity," Journal of Applied Poultry Research, vol. 15, no. 2, pp. 341-351, 2006.

[211] D. J. Nisbet, D. E. Corrier, C. M. Scanlan, A. G. Hollister, R. C. Beier, and J. R. DeLoach, "Effect of a defined continuousflow derived bacterial culture and dietary lactose on Salmonella typhimurium colonization in broiler chickens," Avian Diseases, vol. 37, no. 4, pp. 1017-1025, 1993.

[212] D. J. Nisbet, D. E. Corrier, S. C. Ricke, M. E. Hume, J. A. Byrd II, and J. R. DeLoach, "Cecal propionic acid as a biological indicator of the early establishment of a microbial ecosystem inhibitory to Salmonella in chicks," Anaerobe, vol. 2, no. 6, pp. 345-350, 1996.

[213] D. J. Nisbet, D. E. Corrier, S. C. Ricke, M. E. Hume, J. A. Byrd II, and J. R. Deloach, "Maintenance of the biological efficacy in chicks of a cecal competitive-exclusion culture against Salmonella by continuous-flow fermentation," Journal of Food Protection, vol. 59, no. 12, pp. 1279-1283, 1996.

[214] D. J. Nisbet, R. C. Anderson, D. E. Corrier, R. B. Harvey, and L. H. Stanker, "Modeling the survivability of Salmonella typhimurium in the chicken cecae using an anaerobic continuous-culture of chicken cecal bacteria," Microbial Ecology in Health and Disease, vol. 12, no. 1, pp. 42-47, 2000. 
[215] D. E. Corrier, D. J. Nisbet, A. G. Hollister et al., "Resistance against Salmonella enteritidis cecal colonization in Leghorn chicks by vent lip application of cecal bacteria culture," Poultry Science, vol. 73, no. 5, pp. 648-652, 1994.

[216] R. M. La Ragione and M. J. Woodward, "Competitive exclusion by Bacillus subtilis spores of Salmonella enterica serotype Enteritidis and Clostridium perfringens in young chickens," Veterinary Microbiology, vol. 94, no. 3, pp. 245-256, 2003.

[217] S. E. Higgins, G. F. Erf, J. P. Higgins et al., "Effect of probiotic treatment in broiler chicks on intestinal macrophage numbers and phagocytosis of Salmonella enteritidis by abdominal exudate cells," Poultry Science, vol. 86, no. 11, pp. 2315-2321, 2007.

[218] S. E. Higgins, J. P. Higgins, A. D. Wolfenden et al., "Evaluation of a Lactobacillus-based probiotic culture for the reduction of Salmonella Enteritidis in neonatal broiler chicks," Poultry Science, vol. 87, no. 1, pp. 27-31, 2008.

[219] B. Vilà, A. Fontgibell, I. Badiola et al., "Reduction of Salmonella enterica var. Enteritidis colonization and invasion by Bacillus cereus var. toyoi inclusion in poultry feeds," Poultry Science, vol. 88, no. 5, pp. 975-979, 2009.

[220] D. E. Corrier, D. J. Nisbet, B. M. Hargis, P. S. Holt, and J. R. DeLoach, "Provision of lactose to molting hens enhances resistance to Salmonella enteritidis colonization," Journal of Food Protection, vol. 60, no. 1, pp. 10-15, 1997.

[221] M. E. Hume, L. F. Kubena, T. S. Edrington et al., "Poultry digestive microflora biodiversity as indicated by denaturing gradient gel electrophoresis," Poultry Science, vol. 82, no. 7, pp. 1100-1107, 2003.

[222] R. W. Moore, S. Y. Park, L. F. Kubena et al., "Comparison of zinc acetate and propionate addition on gastrointestinal tract fermentation and susceptibility of laying hens to Salmonella enteritidis during forced molt," Poultry Science, vol. 83, no. 8, pp. 1276-1286, 2004.

[223] S. C. Ricke, S. Y. Park, R. W. Moore et al., "Feeding low calcium and zinc molt diets sustains gastrointestinal fermentation and limits Salmonella enterica serovar Enteritidis colonization in laying hens," Journal of Food Safety, vol. 24, no. 4, pp. 291-308, 2004.

[224] C. L. Woodward, Y. M. Kwon, L. F. Kubena et al., "Reduction of Salmonella enterica serovar Enteritidis colonization and invasion by an alfalfa diet during molt in leghorn hens," Poultry Science, vol. 84, no. 2, pp. 185-193, 2005.

[225] L. M. Donalson, J. L. McReynolds, W. K. Kim et al., "The influence of a fructooligosaccharide prebiotic combined with alfalfa molt diets on the gastrointestinal tract fermentation, Salmonella Enteritidis infection, and intestinal shedding in laying hens," Poultry Science, vol. 87, no. 7, pp. 1253-1262, 2008.

[226] K.-H. Seo, P. S. Holt, and R. K. Gast, "Comparison of Salmonella Enteritidis infection in hens molted via long-term feed withdrawal versus full-fed wheat middling," Journal of Food Protection, vol. 64, no. 12, pp. 1917-1921, 2001.

[227] S. Y. Park, S. G. Birkhold, L. F. Kubena, D. J. Nisbet, and S. C. Ricke, "Review on the role of dietary zinc in poultry nutrition, immunity, and reproduction," Biological Trace Element Research, vol. 101, no. 2, pp. 147-163, 2004.

[228] S. Y. Park, S. G. Birkhold, L. F. Kubena, D. J. Nisbet, and S. C. Ricke, "Effects of high zinc diets using zinc propionate on molt induction, organs, and postmolt egg production and quality in laying hens," Poultry Science, vol. 83, no. 1, pp. 24-33, 2004.

[229] J. McReynolds, L. Kubena, J. Byrd, R. Anderson, S. Ricke, and D. Nisbet, "Evaluation of Salmonella enteritidis (SE) in molting hens after administration of an experimental chlorate product (for nine days) in the drinking water and feeding an alfalfa molt diet," Poultry Science, vol. 84, no. 8, pp. 1186-1190, 2005.

[230] J. L. McReynolds, R. W. Moore, L. F. Kubena et al., "Effect of various combinations of alfalfa and standard layer diet on susceptibility of laying hens to Salmonella Enteritidis during forced molt," Poultry Science, vol. 85, no. 7, pp. 1123-1128, 2006.

[231] U. Babu, M. Scott, M. J. Myers et al., "Effects of live attenuated and killed Salmonella vaccine on T-lymphocyte mediated immunity in laying hens," Veterinary Immunology and Immunopathology, vol. 91, no. 1, pp. 39-44, 2003.

[232] I. Dewaele, G. Rasschaert, C. Wildemauwe et al., "Polyphasic characterization of Salmonella Enteritidis isolates on persistently contaminated layer farms during the implementation of a national control program with obligatory vaccination: a longitudinal study," Poultry Science, vol. 91, no. 11, pp. 2727-2735, 2012.

[233] L. Revolledo and A. J. P. Ferreira, "Current perspectives in avian salmonellosis: vaccines and immune mechanisms of protection," Journal of Applied Poultry Research, vol. 21, no. 2, pp. 418-431, 2012.

[234] L. F. Kubena, J. A. Byrd, R. W. Moore, S. C. Ricke, and D. J. Nisbet, "Effects of drinking water treatment on susceptibility of laying hens to Salmonella enteritidis during forced molt," Poultry Science, vol. 84, no. 2, pp. 204-211, 2005.

[235] L. M. Donalson, W. K. Kim, V. I. Chalova et al., "In vitro fermentation response of laying hen cecal bacteria to combinations of fructooligosaccharide prebiotics with alfalfa or a layer ration," Poultry Science, vol. 87, no. 7, pp. 1263-1275, 2008.

[236] M. Driessen, P. W. Postma, and K. van Dam, "Energetics of glucose uptake in Salmonella typhimurium," Archives of Microbiology, vol. 146, no. 4, pp. 358-361, 1987.

[237] K. G. Maciorowski, D. J. Nisbet, S. D. Ha, D. E. Corrier, J. R. DeLoach, and S. C. Ricke, "Fermentation and growth response of a primary poultry isolate of Salmonella typhimurium grown under strict anaerobic conditions in continuous culture and amino acid-limited batch culture," in Mechanisms in the Pathogenesis of Enteric Diseases, P. S. Paul, D. H. Francis, and D. A. Benfield, Eds., chapter 29, pp. 201-208, Plenum, New York, NY, USA, 1997.

[238] S. C. Ricke, D. J. Nisbet, and K. G. Maciorowski, "Batch culture growth response of a poultry Salmonella typhimurium isolate to ammonium salts," Bioresource Technology, vol. 60, no. 2, pp. 107-111, 1997.

[239] P. W. J. J. van der Wielen, S. Biesterveld, L. J. A. Lipman, and F. van Knapen, "Inhibition of a glucose-limited sequencing fed-batch culture of Salmonella enterica serovar Enteritidis by volatile fatty acids representative of the ceca of broiler chickens," Applied and Environmental Microbiology, vol. 67, no. 4, pp. 1979-1982, 2001.

[240] K. D. Dunkley, T. R. Callaway, V. I. Chalova et al., "Growth and genetic responses of Salmonella Typhimurium to $\mathrm{pH}$-shifts in an anaerobic continuous culture," Anaerobe, vol. 14, no. 1, pp. 35-42, 2008.

[241] K. D. Dunkley, T. R. Callaway, and C. O’Bryan, “Cell yields and fermentation responses of a Salmonella Typhimurium poultry isolate at different dilution rates in an anaerobic steady state continuous culture," Antonie van Leeuwenhoek, vol. 96, no. 4, pp. 537-544, 2009.

[242] K. D. Dunkley, T. R. Callaway, C. A. O’Bryan et al., “Comparison of real time polymerase chain reaction quantification of changes in hilA and rpoS gene expression of a Salmonella typhimurium 
poultry isolate grown at fast versus slow dilution rates in an anaerobic continuous culture system," Food Biotechnology, vol. 26, no. 3, pp. 239-251, 2012.

[243] C. A. Lee and S. Falkow, "The ability of Salmonella to enter mammalian cells is affected by bacterial growth state," Proceedings of the National Academy of Sciences of the United States of America, vol. 87, no. 11, pp. 4304-4308, 1990.

[244] C. A. Lee, B. D. Jones, and S. Falkow, "Identification of a Salmonella typhimurium invasion locus by selection for hyperinvasive mutants," Proceedings of the National Academy of Sciences of the United States of America, vol. 89, no. 5, pp. 18471851, 1992.

[245] V. L. Miller, “Tissue-culture invasion: fact or artefact?” Trends in Microbiology, vol. 3, no. 2, pp. 69-71, 1995.

[246] J. Slauch, R. Taylor, and S. Maloy, "Survival in a cruel world: how Vibrio cholerae and Salmonella respond to an unwilling host," Genes \& Development, vol. 11, no. 14, pp. 1761-1774, 1997.

[247] J. A. Durant, V. K. Lowry, D. J. Nisbet, L. H. Stanker, D. E. Corrier, and S. C. Ricke, "Short-chain fatty acids affect cellassociation and invasion of HEp-2 cells by Salmonella typhimurium," Journal of Environmental Science and Health-Part $B$ Pesticides, Food Contaminants, and Agricultural Wastes, vol. 34, no. 6, pp. 1083-1099, 1999.

[248] J. A. Durant, V. K. Lowry, D. J. Nisbet, L. H. Stanker, D. E. Corrier, and S. C. Ricke, "Late logarithmic Salmonella typhimurium HEp-2 cell association and invasion response to shortchain fatty acid addition," Journal of Food Safety, vol. 20, no. 1, pp. 1-11, 2000.

[249] J. A. Durant, V. K. Lowry, D. J. Nisbet, L. H. Stanker, D. E. Corrier, and S. C. Ricke, "Short chain fatty acids alter HEp-2 cell association and invasion by stationary growth phase Salmonella typhimurium," Journal of Food Science, vol. 65, no. 7, pp. 12061209, 2000.

[250] D. H. Shah, X. Zhou, T. Addwebi, M. A. Davis, and D. R. Call, "In vitro and in vivo pathogenicity of Salmonella enteritidis clinical strains isolated from North America," Archives of Microbiology, vol. 193, no. 11, pp. 811-821, 2011.

[251] V. Bajaj, R. L. Lucas, C. Hwang, and C. A. Lee, "Co-ordinate regulation of Salmonella typhimurium invasion genes by environmental and regulatory factors is mediated by control of hilA expression," Molecular Microbiology, vol. 22, no. 4, pp. 703-714, 1996.

[252] R. H. Valdivia, A. E. Hromockyj, D. Monack, L. Ramakrishnan, and S. Falkow, "Applications for green fluorescent protein (GFP) in the study of host-pathogen interactions," Gene, vol. 173, no. 1, pp. 47-52, 1996.

[253] J. A. Durant, D. E. Corrier, and S. C. Ricke, "Short-chain volatile fatty acids modulate the expression of the hilA and invF genes of Salmonella Typhimurium," Journal of Food Protection, vol. 63, no. 5, pp. 573-578, 2000.

[254] J. A. Durant, D. E. Corrier, L. H. Stanker, and S. C. Ricke, "Expression of the hilA Salmonella typhimurium gene in a poultry Salm, enteritidis isolate in response to lactate and nutrients," Journal of Applied Microbiology, vol. 89, no. 1, pp. 6369, 2000.

[255] J. A. Durant, D. E. Corrier, L. H. Stanker, and S. C. Ricke, "Salmonella enteritidis hilA gene fusion response after incubation in spent media from either S. Enteritidis or a poultry Lactobacillus strain," Journal of Environmental Science and Health B, Pesticides, Food Contaminants, and Agricultural Wastes, vol. 35, no. 5, pp. 599-610, 2000.
[256] J. D. Nutt, L. F. Kubena, D. J. Nisbet, and S. C. Ricke, "Virulence response of a Salmonella Typhimurium hilA:lacZY fusion strain to spent media from pure cultures of selected bacteria and poultry cecal mixed culture," Journal of Food Safety, vol. 22, no. 3, pp. 169-181, 2002.

[257] J. D. Nutt, K. L. Medvedev, C. L. Woodward, S. D. Pillai, and S. C. Ricke, "Assessment of laboratory media controls for determining Salmonella virulence potential of poultry water sources using a hilA:lacZY fusion strain," Journal of Rapid Methods and Automation in Microbiology, vol. 10, no. 3, pp. 173$184,2002$.

[258] J. D. Nutt, S. D. Pillai, C. L. Woodward et al., "Use of a Salmonella Typhimurium hilA fusion strain to assess effects of environmental fresh water sources on virulence gene expression," Water Research, vol. 37, no. 14, pp. 3319-3326, 2003.

[259] F. van Immerseel, J. de Buck, F. Boyen et al., "Medium-chain fatty acids decrease colonization and invasion through hilA suppression shortly after infection of chickens with Salmonella enterica serovar Enteritidis," Applied and Environmental Microbiology, vol. 70, no. 6, pp. 3582-3587, 2004.

[260] I. B. Zabala Díaz and S. C. Ricke, "Influence of short chain fatty acids and lysine on Salmonella typhimurium cadA expression," Antonie van Leeuwenhoek, vol. 85, no. 1, pp. 45-51, 2004.

[261] M. M. Kundinger, I. B. Zabala-Díaz, V. I. Chalova, and S. C. Ricke, "Effects of Maillard reaction products on hilA expression in Salmonella Typhimurium," Journal of Food Science, vol. 73, no. 1, pp. M32-M35, 2008.

[262] A. Kollanoor-Johny, T. Mattson, S. A. Baskaran et al., "Reduction of Salmonella enterica serovar Enteritidis colonization in 20-day-old broiler chickens by the plant-derived compounds trans-cinnamaldehyde and eugenol," Applied and Environmental Microbiology, vol. 78, no. 8, pp. 2981-2987, 2012.

[263] L. Miesel, J. Greene, and T. A. Black, "Genetic strategies for antibacterial drug discovery," Nature Reviews Genetics, vol. 4, no. 6, pp. 442-456, 2003.

[264] J. Rosamond and A. Allsop, "Harnessing the power of the genome in the search for new antibiotics," Science, vol. 287, no. 5460, pp. 1973-1976, 2000.

[265] F. González-Gil, A. Le Bolloch, S. Pendleton, N. Zhang, A. Wallis, and I. Hanning, "Expression of hilA in response to mild acid stress in Salmonella enterica is serovar and strain dependent," Journal of Food Science, vol. 77, no. 5, pp. M292M297, 2012.

[266] R. D. Joerger, C. A. Sartori, and K. E. Kniel, "Comparison of genetic and physiological properties of Salmonella enterica isolates from chickens reveals one major difference between serovar Kentucky and other serovars: response to acid," Foodborne Pathogens and Disease, vol. 6, no. 4, pp. 503-512, 2009.

[267] R. D. Joerger, C. Sartori, J. G. Frye et al., "Gene expression analysis of Salmonella enterica Enteritidis $\mathrm{Nal}^{R}$ and Salmonella enterica Kentucky 3795 exposed to HCL and acetic acid in rich medium," Foodborne Pathogens and Disease, vol. 9, no. 4, pp. 331-337, 2012.

[268] D. H. Shah, C. Casavant, Q. Hawley, T. Addwebi, D. R. Call, and J. Guard, "Salmonella Enteritidis strains from poultry exhibit differential responses to acid stress, oxidative stress, and survival in the egg albumen," Foodborne Pathogens and Disease, vol. 9, no. 3, pp. 258-264, 2012.

[269] D. M. Raskin, R. Seshadri, S. U. Pukatzki, and J. J. Mekalanos, "Bacterial genomics and pathogen evolution," Cell, vol. 124, no. 4, pp. 703-714, 2006. 
[270] D. Becker, M. Selbach, C. Rollenhagen et al., "Robust Salmonella metabolism limits possibilities for new antimicrobials," Nature, vol. 440, no. 7082, pp. 303-307, 2006.

[271] R. R. Isberg, "Identification and analysis of proteins expressed by bacterial pathogens in response to host tissues," in Bacterial Stress Responses, G. Storz and R. Hengge-Aronis, Eds., chapter 20, pp. 289-303, ASM Press, Washington, DC, USA, 2000.

[272] L. Rohmer, D. Hocquet, and S. I. Miller, "Are pathogenic bacteria just looking for food? Metabolism and microbial pathogenesis," Trends in Microbiology, vol. 19, no. 7, pp. 341-348, 2011.

[273] M. A. Fischbach and C. T. Walsh, "Antibiotics for emerging pathogens," Science, vol. 325, no. 5944, pp. 1089-1093, 2009.

[274] J. W.-H. Li and J. C. Vederas, "Drug discovery and natural products: end of an era or an endless frontier?" Science, vol. 325, no. 5937, pp. 161-165, 2009.

[275] P. Hieter and M. Boguski, "Functional genomics: it's all how you read it," Science, vol. 278, no. 5338, pp. 601-602, 1997.

[276] B. B. Finlay and J. H. Brumell, "Salmonella interactions with host cells: in vitro to in vivo," Philosophical Transactions of the Royal Society B: Biological Sciences, vol. 355, no. 1397, pp. 623631, 2000.

[277] P. Carninci, "Is sequencing enlightenment ending the dark age of the transcriptome?" Nature Methods, vol. 6, no. 10, pp. 711713, 2009.

[278] F. Calenge and C. Beaumont, "Toward integrative genomics study of genetic resistance to Salmonella and Campylobacter intestinal colonization in fowl," Frontiers in Genetics, vol. 3, article 261, 2012.

[279] S. H. Park, I. Hanning, A. Perrota, B. J. Bench, E. Alm, and S. C. Ricke, "Modifying the gastrointestinal ecology in alternatively raised poultry and the potential for molecular and metabolomic assessment," Poultry Science, vol. 92, no. 2, pp. 546-561, 2013.

[280] T. R. Klaenhammer, E. Pfeiler, and T. Duong, "Genomics and proteomics of foodborne microorganisms," in Food Microbiology-Fundamentals and Frontiers, M. P. Doyle and L. R. Beuchat, Eds., chapter 44, pp. 935-951, ASM Press, Washington, DC, USA, 3rd edition, 2007.

[281] M. M. Reynolds, R. Canals, M. McClelland, and H. L. AndrewsPolymenis, "High-throughput screening to determine the genetic requirements for Salmonella survival under different growth conditions," in Salmonella: From Genome to Function, S. Porwollik, Ed., chapter 4, pp. 69-89, Caister Academic Press, Norflock, UK, 2011.

[282] T. Johnstone, "Under the microscope," Meatingplace Jan: 2830,32,34,36,38,40, 2014.

[283] S. J. O'Brien, "The "Decline and Fall" of nontyphoidal Salmonella in the United Kingdom," Clinical Infectious Diseases, vol. 56, no. 5, pp. 705-710, 2013.

[284] Z. Zhang-Barber, A. K. Turner, and P. A. Barrow, "Vaccination for control of Salmonella in poultry," Vaccine, vol. 17, no. 20-21, pp. 2538-2545, 1999.

[285] P. A. Barrow, G. C. Mead, C. Wray, and M. Duchet-Suchaux, "Control of food-poisoning salmonella in poultry-biological options," World's Poultry Science Journal, vol. 59, no. 3, pp. 373383,2003

[286] H. G. Griffin, "Attenuated Salmonella as live vaccines: prospects for multivalent poultry vaccines," World's Poultry Science Journal, vol. 47, pp. 129-140, 1991.

[287] A. Detmer and J. Glenting, "Live bacterial vaccines-a review and identification of potential hazards," Microbial Cell Factories, vol. 5, article 23, 2006.
[288] C. Gamazo and J. M. Irache, "Salmonella vaccines", in Communicating Current Research and Educational Topics and Trends in Applied Microbiology, A. Méndez-Vilas, Ed., vol. 1, pp. 518-524, Formatex Research Center, Badajoz, Spain, 2007.

[289] P. Mastroeni, J. A. Chabalgoity, S. J. Dunstan, D. J. Maskell, and G. Dougan, "Salmonella: immune responses and vaccines," The Veterinary Journal, vol. 161, no. 2, pp. 132-164, 2001.

[290] R. Curtiss III, S. M. Kelly, and J. O. Hassan, "Live oral avirulent Salmonella vaccines," Veterinary Microbiology, vol. 37, no. 3-4, pp. 397-405, 1993.

[291] R. Curtiss III and J. O. Hassan, "Nonrecombinant and recombinant avirulent Salmonella vaccines for poultry," Veterinary Immunology and Immunopathology, vol. 54, no. 1-4, pp. 365372, 1996.

[292] L. Bohez, R. Ducatelle, F. Pasmans, N. Botteldoorn, F. Haesebrouck, and F. van Immerseel, "Salmonella enterica serovar Enteritidis colonization of the chicken caecum requires the HilA regulatory protein," Veterinary Microbiology, vol. 116, no. 1-3, pp. 202-210, 2006.

[293] L. Bohez, R. Ducatelle, F. Pasmans, F. Haesebrouck, and F. van Immerseel, "Long-term colonisation-inhibition studies to protect broilers against colonisation with Salmonella Enteritidis, using Salmonella pathogenicity island 1 and 2 mutants," Vaccine, vol. 25, no. 21, pp. 4235-4243, 2007.

[294] K. A. Datsenko and B. L. Wanner, "One-step inactivation of chromosomal genes in Escherichia coli K-12 using PCR products," Proceedings of the National Academy of Sciences of the United States of America, vol. 97, no. 12, pp. 6640-6645, 2000.

[295] D. Zhou, M. S. Mooseker, and J. E. Galán, "Role of the $S$. typhimurium actin-binding protein SipA in bacterial internalization," Science, vol. 283, no. 5410, pp. 2092-2095, 1999.

[296] M. Hensel, "Salmonella pathogenicity island 2," Molecular Microbiology, vol. 36, no. 5, pp. 1015-1023, 2000.

[297] C. Altier, "Genetic and environmental control of Salmonella invasion," Journal of Microbiology, vol. 43, pp. 85-92, 2005.

[298] L. Bohez, J. Dewulf, R. Ducatelle, F. Pasmans, F. Haesebrouck, and F. van Immerseel, "The effect of oral administration of a homologous hilA mutant strain on the long-term colonization and transmission of Salmonella Enteritidis in broiler chickens," Vaccine, vol. 26, no. 3, pp. 372-378, 2008.

[299] D. Karasova, A. Sebkova, V. Vrbas, H. Havlickova, F. Sisak, and I. Rychlik, "Comparative analysis of Salmonella enterica serovar Enteritidis mutants with a vaccine potential," Vaccine, vol. 27, no. 38, pp. 5265-5270, 2009.

[300] I. Rychlik, D. Karasova, A. Sebkova et al., "Virulence potential of five major pathogenicity islands (SPI-1 to SPI-5) of Salmonella enterica serovar Enteritidis for chickens," BMC Microbiology, vol. 9, article 268, 2009.

[301] Y. Dieye, K. Ameiss, M. Mellata, and R. Curtiss III, "The Salmonella pathogenicity island (SPI) 1 contributes more than SPI2 to the colonization of the chicken by Salmonella enterica serovar Typhimurium," BMC Microbiology, vol. 9, article 3, 2009.

[302] D. Karasova, H. Havlickova, F. Sisak, and I. Rychlik, "Deletion of sodCI and spvBC in Salmonella enterica serovar Enteritidis reduced its virulence to the natural virulence of serovars Agona, Hadar and Infantis for mice but not for chickens early after infection," Veterinary Microbiology, vol. 139, no. 3-4, pp. 304309, 2009.

[303] J. Volf, F. Boyen, M. Faldyna, B. Pavlova, J. Navratilova, and I. Rychlik, "Cytokine response of porcine cell lines to Salmonella 
enterica serovar Typhimurium and its hilA and ssrA mutants," Zoonoses and Public Health, vol. 54, no. 8, pp. 286-293, 2007.

[304] H. He, K. J. Genovese, C. L. Swaggerty, D. J. Nisbet, and M. H. Kogut, "A comparative study on invasion, survival, modulation of oxidative burst, and nitric oxide responses of macrophages (HD11), and systemic infection in chickens by prevalent poultry Salmonella serovars," Foodborne Pathogens and Disease, vol. 9, no. 12, pp. 1104-1110, 2012.

[305] X. Zhang, S. M. Kelly, W. Bollen, and R. Curtiss III, "Protection and immune responses induced by attenuated Salmonella typhimurium UK-1 strains," Microbial Pathogenesis, vol. 26, no. 3, pp. 121-130, 1999.

[306] D. H. Shah, X. Zhou, T. Addwebi et al., "Cell invasion of poultryassociated Salmonella enterica serovar Enteritidis isolates is associated with pathogenicity, motility and proteins secreted by the type III secretion system," Microbiology, vol. 157, no. 5, pp. 1428-1445, 2011.

[307] Y. Luo, Q. Kong, J. Yang et al., “Comparative genome analysis of the high pathogenicity Salmonella typhimurium strain UK1," PLoS ONE, vol. 7, no. 7, Article ID e40645, 2012.

[308] C. R. Roy and E. S. Mocarski, "Pathogen subversion of cellintrinsic innate immunity," Nature Immunology, vol. 8, no. 11, pp. 1179-1187, 2007.

[309] I. E. Brodsky and R. Medzhitov, "Targeting of immune signalling networks by bacterial pathogens," Nature Cell Biology, vol. 11, no. 5, pp. 521-526, 2009.

[310] L. Diacovich and J. P. Gorvel, "Bacterial manipulation of innate immunity to promote infection," Nature Reviews Microbiology, vol. 8, no. 2, pp. 117-128, 2010.

[311] R. M. Tsolis, M. N. Xavier, R. L. Santos, and A. J. Bäumler, "How to become a top model: impact of animal experimentation on human Salmonella disease research," Infection and Immunity, vol. 79, no. 5, pp. 1806-1814, 2011.

[312] S. H. E. Kaufmann, B. Raupach, and B. Brett Finlay, "Introduction: microbiology and immunology: lessons learned from Salmonella," Microbes and Infection, vol. 3, no. 14-15, pp. 11771181, 2001.

[313] E. Medina and C. A. Guzmán, "Use of live bacterial vaccine vectors for antigen delivery: potential and limitations," Vaccine, vol. 19, no. 13-14, pp. 1573-1580, 2001.

[314] K. Hallstrom and B. A. McCormick, "Salmonella interaction with and passage through the intestinal mucosa: through the lens of the organism," Frontiers in Microbiology, vol. 2, article 88, 2011.

[315] P. Malik-Kale, C. E. Jolly, S. Lathrop, S. Winfree, C. Luterbach, and O. Steele-Mortimer, "Salmonella-at home in the host cell," Frontiers in Microbiology, vol. 2, article 125, 2011.

[316] T. Dandekar, A. Fieselmann, J. Popp, and M. Hensel, "Salmonella enterica: a surprisingly well-adapted intracellular lifestyle," Frontiers in Microbiology, vol. 3, article 164, 2012.

[317] S. K. Hoiseth and B. A. D. Stocker, "Aromatic-dependent Salmonella typhimurium are non-virulent and effective as live vaccines," Nature, vol. 291, no. 5812, pp. 238-239, 1981.

[318] S. K. Hoiseth and B. A. D. Stocker, "Genes $\operatorname{aroA}$ and $\operatorname{serC}$ of Salmonella typhimurium constitute an operon," Journal of Bacteriology, vol. 163, no. 1, pp. 355-361, 1985.

[319] N. C. Molina and C. D. Parker, "Murine antibody response to oral infection with live aroA recombinant Salmonella dublin vaccine strains expressing filamentous hemagglutinin antigen from Bordetella pertussis," Infection and Immunity, vol. 58, no. 8, pp. 2523-2528, 1990.
[320] K. Linde, G. C. Fthenakis, and A. Fichtner, "Bacterial vaccines with graded level of attenuation achieved by antibiotic resistance mutations: transduction experiments on the unit of resistance, attenuation and further accompanying markers," Veterinary Microbiology, vol. 66, pp. 121-134, 1998.

[321] L. N. Calhoun and Y.-M. Kwon, "Salmonella-based plague vaccines for bioterrorism," Journal of Microbiology, Immunology and Infection, vol. 39, no. 2, pp. 92-97, 2006.

[322] R. Stratford, N. D. McKelvie, N. J. Hughes et al., "Optimization of Salmonella enterica serovar Typhi $\Delta a r o C \Delta s s a V$ derivatives as vehicles for delivering heterologous antigens by chromosomal integration and in vivo inducible promoters," Infection and Immunity, vol. 73, no. 1, pp. 362-368, 2005.

[323] S. Wang, Q. Kong, and R. Curtiss III, "New technologies in developing recombinant attenuated Salmonella vaccine vectors," Microbial Pathogenesis, vol. 58, pp. 17-28, 2013.

[324] R. Curtiss III, J. E. Galan, K. Nakayama, and S. M. Kelly, "Stabilization of recombinant avirulent vaccine strains in vivo," Research in Microbiology, vol. 141, no. 7-8, pp. 797-805, 1990.

[325] J. E. Galán, K. Nakayama, and R. Curtiss III, "Cloning and characterization of the asd gene of Salmonella typhimurium: use in stable maintenance of recombinant plasmids in Salmonella vaccine strains," Gene, vol. 94, no. 1, pp. 29-35, 1990.

[326] D. W. Pascual, D. M. Hone, S. Hall et al., "Expression of recombinant enterotoxigenic Escherichia coli colonization factor antigen I by Salmonella typhimurium elicits a biphasic $\mathrm{T}$ helper cell response," Infection and Immunity, vol. 67, no. 12, pp. 6249-6256, 1999.

[327] H. V. McNeill, K. A. Sinha, C. E. Hormaeche, J. J. Lee, and C. M. A. Khan, "Development of a nonantibiotic dominant marker for positively selecting expression plasmids in multivalent Salmonella vaccines," Applied and Environmental Microbiology, vol. 66, no. 3, pp. 1216-1219, 2000.

[328] M. I. Husseiny and M. Hensel, "Rapid method for the construction of Salmonella enterica serovar Typhimurium vaccine carrier strains," Infection and Immunity, vol. 73, no. 3, pp. 15981605, 2005.

[329] N. Walters, T. Trunkle, M. Sura, and D. W. Pascual, "Enhanced immunoglobulin A response and protection against Salmonella enterica serovar Typhimurium in the absence of the substance $\mathrm{P}$ receptor," Infection and Immunity, vol. 73, no. 1, pp. 317-324, 2005.

[330] J. E. Galen, J. Nair, J. Y. Wang et al., "Optimization of plasmid maintenance in the attenuated live vector vaccine strain Salmonella typhi CVD 908-htrA," Infection and Immunity, vol. 67, no. 12, pp. 6424-6433, 1999.

[331] K. Panthel, K. M. Meinel, V. E. S. Domènech et al., "Salmonella pathogenicity island 2-mediated overexpression of chimeric $\mathrm{SspH} 2$ proteins for simultaneous induction of antigen-specific CD4 and CD8 T cells," Infection and Immunity, vol. 73, no. 1, pp. 334-341, 2005

[332] J. E. Galen and M. M. Levine, "Can a "flawless" live vector vaccine strain be engineered?" Trends in Microbiology, vol. 9, no. 8, pp. 372-376, 2001.

[333] R. A. Strugnell, D. Maskell, N. Fairweather et al., "Stable expression of foreign antigens from the chromosome of Salmonella typhimurium vaccine strains," Gene, vol. 88, no. 1, pp. 57-63, 1990.

[334] I. Hautefort, M. J. Proença, and J. C. D. Hinton, "Singlecopy green fluorescent protein gene fusions allow accurate measurement of Salmonella gene expression in vitro and during 
infection of mammalian cells," Applied and Environmental Microbiology, vol. 69, no. 12, pp. 7480-7491, 2003.

[335] S. Uzzau, N. Figueroa-Bossi, S. Rubino, and L. Bossi, "Epitope tagging of chromosomal genes in Salmonella," Proceedings of the National Academy of Sciences of the United States of America, vol. 98, no. 26, pp. 15264-15269, 2001.

[336] M. I. Husseiny and M. Hensel, "Evaluation of an intracellularactivated promoter for the generation of live Salmonella recombinant vaccines," Vaccine, vol. 23, no. 20, pp. 2580-2590, 2005.

[337] E. L. Hohmann, C. A. Oletta, W. P. Loomis, and S. I. Miller, "Macrophage-inducible expression of a model antigen in Salmonella typhimurium enhances immunogenicity," Proceedings of the National Academy of Sciences of the United States of America, vol. 92, no. 7, pp. 2904-2908, 1995.

[338] B. K. Tischer, J. von Einem, B. Kaufer, and N. Osterrieder, "Two-step Red-mediated recombination for versatile highefficiency markerless DNA manipulation in Escherichia coli," BioTechniques, vol. 40, no. 2, pp. 191-196, 2006.

[339] K. Kaniga, I. Delor, and G. R. Cornelis, "A wide-host-range suicide vector for improving reverse genetics in Gram-negative bacteria: inactivation of the blaA gene of Yersinia enterocolitica," Gene, vol. 109, no. 1, pp. 137-141, 1991.

[340] Y. Zhang, F. Buchholz, J. P. P. Muyrers, and A. Francis Stewart, "A new logic for DNA engineering using recombination in Escherichia coli," Nature Genetics, vol. 20, no. 2, pp. 123-128, 1998.

[341] S. Warming, N. Costantino, D. L. Court, N. A. Jenkins, and N. G. Copeland, "Simple and highly efficient BAC recombineering using galK selection," Nucleic Acids Research, vol. 33, article e36, 2005.

[342] Q. N. Y. Wong, V. C. W. Ng, C. C. M. Lin, H. F. Kung, D. Chan, and J. D. Huang, "Efficient and seamless DNA recombineering using a thymidylate synthase A selection system in Escherichia coli," Nucleic Acids Research, vol. 33, article e59, 2005.

[343] G. Pósfai, V. Kolisnychenko, Z. Bereczki, and F. R. Blattner, "Markerless gene replacement in Escherichia coli stimulated by a double-strand break in the chromosome," Nucleic Acids Research, vol. 27, no. 22, pp. 4409-4415, 1999.

[344] D. Jamsai, M. Orford, M. Nefedov, S. Fucharoen, R. Williamson, and P. A. Ioannou, "Targeted modification of a human $\beta$-globin locus BAC clone using GET Recombination and an I-SceI counterselection cassette," Genomics, vol. 82, no. 1, pp. 68-77, 2003.

[345] Y. Kang, T. Durfee, J. D. Glasner et al., "Systematic mutagenesis of the Escherichia coli genome," Journal of Bacteriology, vol. 186, pp. 4921-4930, 2004.

[346] M. M. Cox, S. L. Layton, T. Jiang et al., "Scarless and sitedirected mutagenesis in Salmonella Enteritidis chromosome," BMC Biotechnology, vol. 7, article 59, 2007.

[347] S. L. Layton, D. R. Kapczynski, S. Higgins et al., "Vaccination of chickens with recombinant Salmonella expressing M2e and CD154 epitopes increases protection and decreases viral shedding after low pathogenic avian influenza challenge," Poultry Science, vol. 88, no. 11, pp. 2244-2252, 2009.

[348] K. M. O’Meara, C. J. Kremer, S. L. Layton, L. R. Berghman, B. M. Hargis, and K. Cole, "Evaluation of recombinant Salmonella expressing cd154 for persistence and enhanced antibody response in commercial turkeys," Poultry Science, vol. 89, no. 7, pp. 1399-1405, 2010.
[349] R. E. Wolfenden, S. L. Layton, A. D. Wolfenden et al., "Development and evaluation of candidate recombinant Salmonellavectored Salmonella vaccines," Poultry Science, vol. 89, no. 11, pp. 2370-2379, 2010.

[350] C. J. Kremer, K. M. O’Meara, S. L. Layton, B. M. Hargis, and K. Cole, "Evaluation of recombinant Salmonella expressing the flagellar protein fliC for persistence and enhanced antibody response in commercial turkeys," Poultry Science, vol. 90, no. 4, pp. 752-758, 2011.

[351] T. S. Wallis, "Salmonella pathogenesis and immunity: we need effective multivalent vaccines," Veterinary Journal, vol. 161, no. 2, pp. 104-106, 2001.

[352] R. B. R. Ferreira and B. B. Finlay, "Identifying an immune signature against invasive Salmonella," Proceedings of the National Academy of Sciences of the United States of America, vol. 109, no. 13, pp. 4721-4722, 2012.

[353] S.-J. Lee, L. Liang, S. Juarez et al., "Identification of a common immune signature in murine and human systemic salmonellosis," Proceedings of the National Academy of Sciences of the United States of America, vol. 109, no. 13, pp. 4998-5003, 2012.

[354] P. A. Barrow, M. A. Jones, A. L. Smith, and P. Wigley, “The long view: Salmonella - the last forty years," Avian Pathology, vol. 41, no. 5, pp. 413-420, 2012.

[355] J. W. Foster and M. P. Spector, "How Salmonella survive against the odds," Annual Review of Microbiology, vol. 49, pp. 145-174, 1995.

[356] M. P. Spector, "The starvation-stress response (SSR) of Salmonella," Advances in Microbial Physiology, vol. 40, pp. 233279, 1998.

[357] B. D. Jones, "Salmonella invasion gene regulation: a story of environmental awareness," Journal of Microbiology, vol. 43, pp. 110-117, 2005.

[358] A. R. Horswill, A. R. Dudding, and J. C. Escalante-Semerena, "Studies of propionate toxicity in Salmonella enterica identify 2- methylcitrate as a potent inhibitor of cell growth," Journal of Biological Chemistry, vol. 276, no. 22, pp. 19094-19101, 2001.

[359] S. M. D. Bearson, B. L. Bearson, and M. A. Rasmussen, "Identification of Salmonella enterica serovar Typhimurium genes important for survival in the swine gastric environment," Applied and Environmental Microbiology, vol. 72, no. 4, pp. 2829-2836, 2006.

[360] Y. Huang, M. Suyemoto, C. D. Garner, K. M. Cicconi, and C. Altier, "Formate acts as a diffusible signal to induce Salmonella invasion," Journal of Bacteriology, vol. 190, no. 12, pp. 4233-4241, 2008.

[361] L. N. Calhoun and Y. M. Kwon, "The effect of long-term propionate adaptation on the stress resistance of Salmonella Enteritidis," Journal of Applied Microbiology, vol. 109, no. 4, pp. 1294-1300, 2010.

[362] C. J. Rocco and J. C. Escalante-Semerena, "In Salmonella enterica, 2-methylcitrate blocks gluconeogenesis," Journal of Bacteriology, vol. 192, no. 3, pp. 771-778, 2010.

[363] M. E. Jennings, L. N. Quick, A. Soni et al., "Characterization of the Salmonella enterica serovar typhimurium $y d c I$ gene, which encodes a conserved DNA binding protein required for full acid stress resistance," Journal of Bacteriology, vol. 193, no. 9, pp. 2208-2217, 2011.

[364] C.-C. Hung, C. D. Garner, J. M. Slauch et al., "The intestinal fatty acid propionate inhibits Salmonella invasion through the posttranslational control of HilD," Molecular Microbiology, vol. 87, no. 5, pp. 1045-1060, 2013. 
[365] R. L. Santos, M. Raffatellu, C. L. Bevins et al., "Life in the inflamed intestine, Salmonella style," Trends in Microbiology, vol. 17, no. 11, pp. 498-506, 2009.

[366] S. E. Winter, P. Thiennimitr, M. G. Winter et al., "Gut inflammation provides a respiratory electron acceptor for Salmonella," Nature, vol. 467, no. 7314, pp. 426-429, 2010.

[367] S. E. Winter and A. J. Bäumler, "Salmonella exploits suicidal behavior of epithelial cells," Frontiers in Microbiology, vol. 2, article 48, pp. 1-2, 2011.

[368] B. M. M. Ahmer and J. S. Gunn, "Interaction of Salmonella spp. with the intestinal microbiota," Frontiers in Microbiology, vol. 2, article 101, 2011.

[369] H. Steenackers, K. Hermans, J. Vanderleyden, and S. C. J. de Keersmaecker, "Salmonella biofilms: an overview on occurrence, structure, regulation and eradication," Food Research International, vol. 45, no. 2, pp. 502-531, 2012.

[370] S. C. J. de Keersmaeckert, C. Varszegi, N. van Boxel et al., "Chemical synthesis of (S)-4,5-dihydroxy-2,3-pentanedione, a bacterial signal molecule precursor, and validation of its activity in Salmonella typhimurium," Journal of Biological Chemistry, vol. 280, no. 20, pp. 19563-19568, 2005.

[371] S. C. J. de Keersmaecker, K. Sonck, and J. Vanderleyden, "Let LuxS speak up in AI-2 signaling," Trends in Microbiology, vol. 14, no. 3, pp. 114-119, 2006.

[372] J. C. A. Janssens, K. Metzger, R. Daniels et al., "Synthesis of $\mathrm{N}$-acyl homoserine lactone analogues reveals strong activators of SdiA, the Salmonella enterica serovar Typhimurium LuxR homologue," Applied and Environmental Microbiology, vol. 73, no. 2, pp. 535-544, 2007.

[373] J. L. Smith, P. M. Fratamico, and J. S. Novak, "Quorum sensing: a primer for food microbiologists," Journal of Food Protection, vol. 67, no. 5, pp. 1053-1070, 2004.

[374] K. W. Widmer, K. A. Soni, M. E. Hume, R. C. Beier, P. Jesudhasan, and S. D. Pillai, "Identification of poultry meat-derived fatty acids functioning as quorum sensing signal inhibitors to autoinducer-2 (AI-2)," Journal of Food Science, vol. 72, no. 9, pp. M363-M368, 2007.

[375] J. D. Boddicker, N. A. Ledeboer, J. Jagnow, B. D. Jones, and S. Clegg, "Differential binding to and biofilm formation on, HEp-2 cells by Salmonella enterica serovar Typhimurium is dependent upon allelic variation in the fimH gene of the fim gene cluster," Molecular Microbiology, vol. 45, no. 5, pp. 1255-1265, 2002.

[376] N. A. Ledeboer and B. D. Jones, "Exopolysaccharide sugars contribute to biofilm formation by Salmonella enterica serovar Typhimurium on HEp-2 cells and chicken intestinal epithelium," Journal of Bacteriology, vol. 187, no. 9, pp. 3214-3226, 2005.

[377] K. W. Widmer, P. Jesudhasan, and S. D. Pillai, "Fatty acid modulation of autoinducer (AI-2) influenced growth and macrophage invasion by Salmonella Typhimurium," Foodborne Pathogens and Disease, vol. 9, no. 3, pp. 211-217, 2012.

[378] A. Lianou and K. P. Koutsoumanis, "Strain variability of the behavior of foodborne bacterial pathogens: a review," International Journal of Food Microbiology, vol. 167, no. 3, pp. 310-321, 2013. 

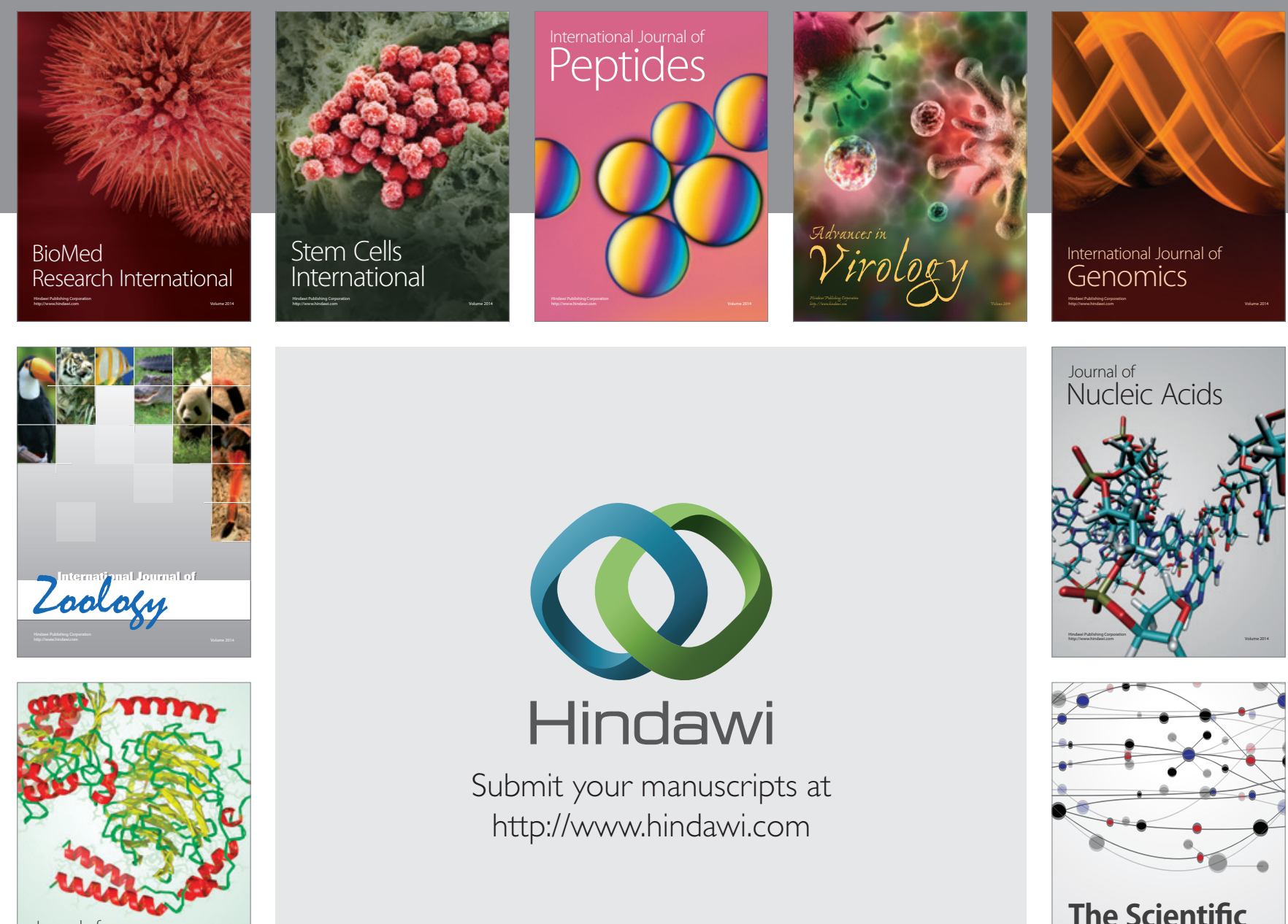

Submit your manuscripts at

http://www.hindawi.com

Journal of
Signal Transduction
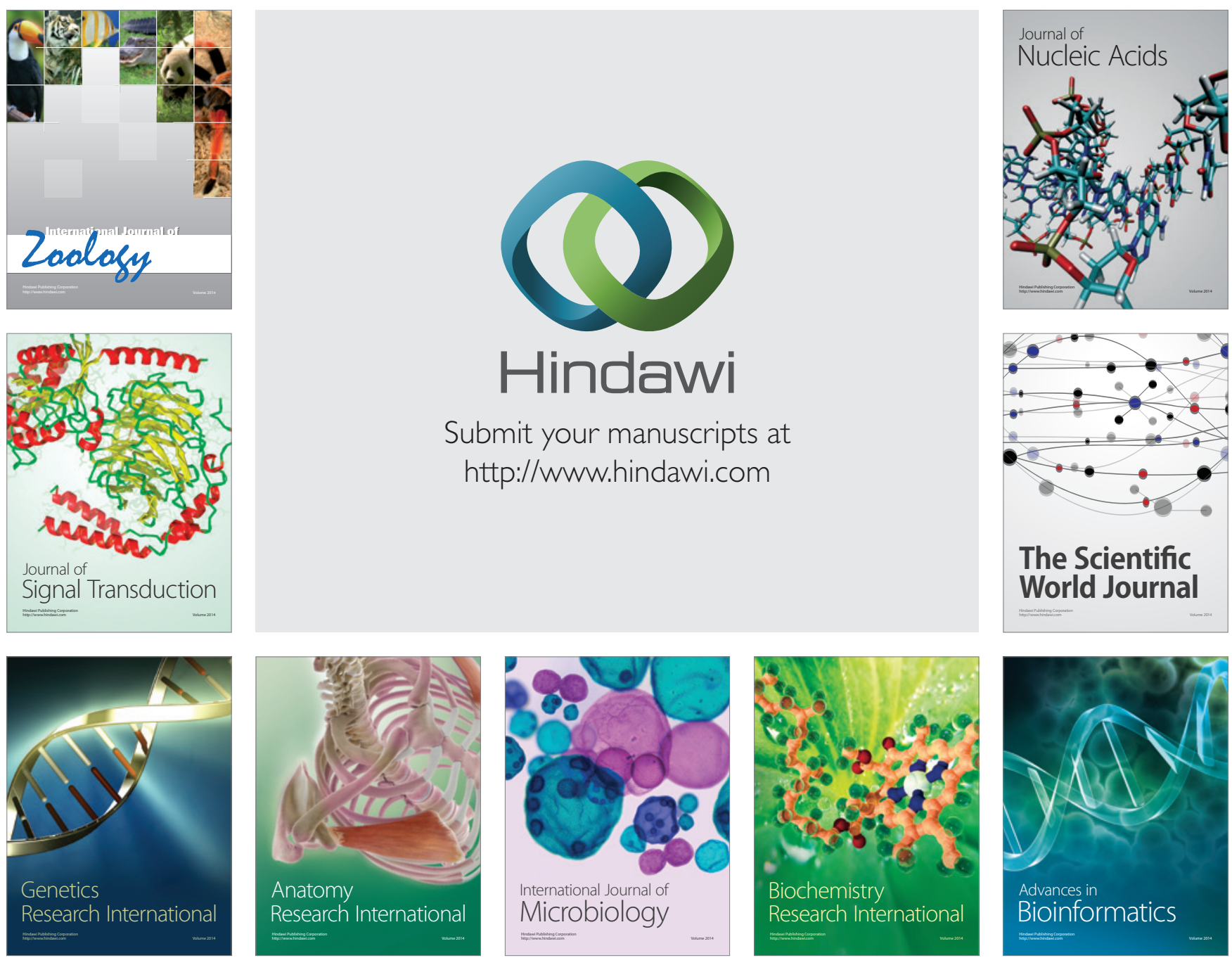

The Scientific World Journal
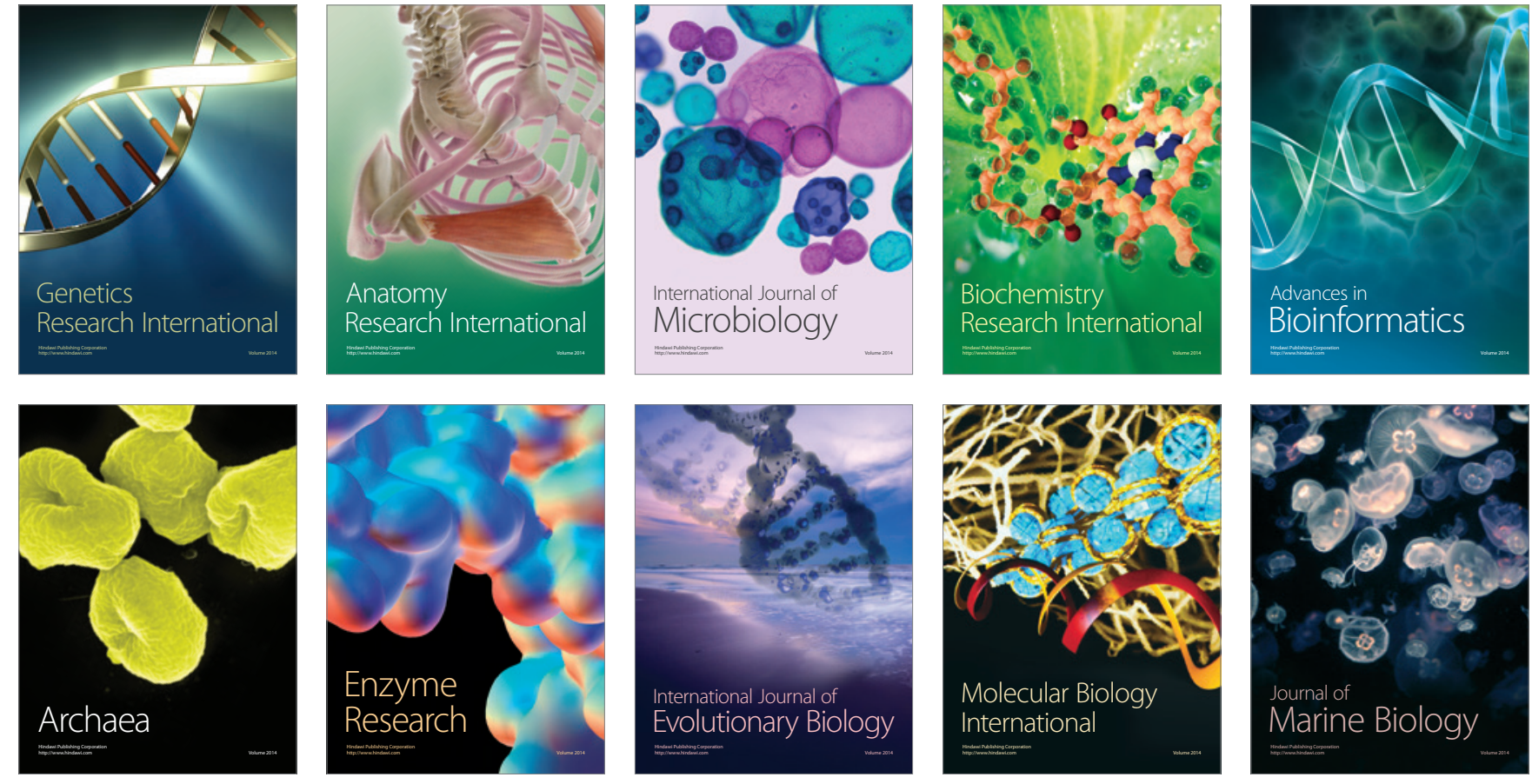